1 Revisiting Panda 100, the first archaeological chimpanzee

\title{
nut-cracking site
}

$6{ }^{1}$ Institute of Archaeology, University College London, 31-34 Gordon Square, London, WC1H 0PY

$7 \quad{ }^{2}$ Primate Archaeology Research Group, School of Archaeology, University of Oxford, Dyson Perrins

8 Building, South Parks Road, Oxford OX1 3QY, United Kingdom

$9{ }^{3}$ Department of Anthropology and Archaeology, University of Calgary, 2500 University Dr., NW

10 Calgary, Alberta T2N 1N4, Canada

$11{ }^{4}$ Department of Primatology, Max Plank Institute for Evolutionary Anthropology, Deutscher Platz 6,

12 D - 04103 Leipzig, Germany

$13{ }^{5}$ School of Anthropology and Museum Ethnography, University of Oxford, Oxford, OX2 6PE, UK.

* Corresponding Author: t.proffitt@ucl.ac.uk 


\section{Abstract}

28 Archaeological recovery of chimpanzee Panda oleosa nut cracking tools at the Panda 100 (P100) and

29 Noulo sites in the Taï Forest, Ivory Coast, showed that this behaviour is over 4,000 years old, making

30 it the oldest known evidence of non-human tool use. In 2002, the first report on P100 directly compared

31 its lithic assemblage to early hominin stone tools, highlighting their similarities and proposing the name

32 'Pandan' for the chimpanzee material. Here we present an expanded and comprehensive technological,

33 microscopic, and refit analysis of the lithic assemblage from P100. Our re-analysis provides new data

34 and perspectives on the applicability of chimpanzee nut cracking tools to our understanding of the

35 percussive behaviours of early hominins. We identify several new refit sets, including the longest

36 hammerstone transport seen in the chimpanzee archaeological record. We provide detailed evidence of

37 the fragmentation sequences of Panda nut hammerstones, and characterise the percussive damage on

38 fragmented material from P100. Finally, we emphasise that the chimpanzee lithic archaeological record

39 is dynamic, with the preservation of actual hammerstones being rare, and the preservation of small

40 broken pieces more common. P100 - the first archaeological chimpanzee nut cracking lithic assemblage

41 - provides a valuable comparative sample by which to identify past chimpanzee behaviour elsewhere,

42 as well as similar hominin percussive behaviour in the Early Stone Age.

44 Keywords: Primate Archaeology; Panda 100; Lithic Analysis; West African Chimpanzee; Primate

45 Tool Use; Percussive Technology; Refit; Pan troglodytes verus 


\section{Introduction}

50 Discussions of the evolution of tool use have historically centred on the hominin lineage: Homo sapiens and our ancestors since we split from the other apes (Harmand et al., 2015; Leakey, 1971). Hominin technological evolution is recorded in a durable record of stone tools, which provide detailed information about our cultural and cognitive development, extending back more than 3.3 million years (Harmand et al., 2015). In contrast, our understanding of the technological evolution of non-human primates is in its infancy. The emerging field of primate archaeology addresses this imbalance using modern archaeological techniques to understand the emergence and development of primate tool use, and to provide new comparative insights into the emergence of hominin lithic technology (Haslam, 2012, Haslam et al, 2017).

Owing to their close relatedness to humans, and their propensity to use a variety of tools, chimpanzees received the earliest and most intense attention as a potential model species for understanding early hominin stone tool use. Some West African chimpanzees (Pan troglodytes verus) use stone tools in the wild, primarily to crack open different nut species. Two long term study sites - Bossou in Guinea and the Taï National Park in Côte d'Ivoire - provide the majority of the research data on this behaviour. In the Taï National Park chimpanzees crack open five different nut species (Panda oleosa, Parinari excelsa, Saccoglottis gabonensis, Coula edulis, and Detarium senegalensis). To crack open the very hard $P$. oleosa nuts chimpanzees use stone tools that vary in size between 3 and $15 \mathrm{~kg}$ (Boesch and Boesch, 1984a), and mostly tree roots for anvils. The uneven distribution of stone material throughout the forest means that chimpanzees need to transport hammerstones to supply Panda nut trees with suitable tool material (Boesch and Boesch, 1984a; Luncz et al., 2016). In 2002, Mercader et al. published a pioneering study from the Taï Forest, proving that inactive chimpanzee stone tool behavioural sites are identifiable in the archaeological record. For the first time researchers demonstrated that a primate material record existed and could be traced, using archaeological techniques, into antiquity. In addition, Mercader et al. (2002) suggested that the chimpanzee artefactual record uncovered at their research site Panda 100 (P100) mimicked early hominin lithic technology. Specific attention was paid to its apparent similarities to Early Stone Age (ESA) lithic assemblages from Omo 123 (Chavaillon, 1976, 1970; de la Torre, 2004), the Shungura formation (FtJi1) (Merrick et al., 1973; Merrick and Merrick, 1976) and KBS Member (Koobi Fora, Kenya) (Isaac, 1976). This led to the suggestion that some lithic material from such Oldowan assemblages may derive from nut cracking behaviour, or the processing of other hard-object foods. This

80 finding contributed directly to the emergence of primate archaeology as a new discipline, combining both archaeological techniques and primate behavioural observations (Haslam et al., 2016a, 2016b, 
2009 , 2017). Here, we apply the latest primate archaeological methods to the P100 lithic assemblage, providing new insights into the relevance of this material for interpreting hominin behaviour (Haslam, 2012).

\section{Background}

The P100 site was a known modern chimpanzee nut cracking location. The 100 square meter excavation at the site yielded a substantial artefactual record, including both lithics and organic remains in the form of abundant nut shells and wooden anvils. This study was joined by subsequent excavations at Noulo and Sacoglotis B, dated to over 4,000 years ago, and located within a hundred metres of P100 (Mercader et al., 2007). The stones recovered from P100 were proposed as the 'Pandan' type assemblage, that is, the type assemblage against which future chimpanzee archaeological finds could be assessed (Mercader et al., 2002).

Although not explicitly stating that hominin-like conchoidal flake technology was represented at P100, Mercader et al. identified numerous pieces that they classified as 'flakes' within the assemblage, noting that 'panins may have been capable of producing assemblages that mimic some of the earliest hominin artifacts' (Mercader et al., 2002, p1455). The apparent similarity of the P100 lithic assemblage to Oldowan hominin stone tool technology has been discussed and contested by a number of researchers (de la Torre, 2004; Delagnes and Roche, 2005; Harmand et al., 2015; Pelegrin, 2005; Schick and Toth, 2006).

Since the initial publication of the P100 material, the study of non-flaking percussive technology has taken a far more prominent and important role in the study of early hominin lithic technology and human evolution. For example, re-analysis of the Omo Oldowan lithic assemblages have argued for the presence of relatively structured exploitation strategies there, including the structured production of fully conchoidal flakes (de la Torre, 2004). Both the quality and diminutive dimensions of the available raw material at Omo are a major factor in the apparently simple nature of the assemblages, and de la 108 Torre et al. (2004) found that any similarity to the P100 lithic material was only in terms of dimensions. 109 The lithic material produced by early hominins appeared qualitatively different to that identified at 110 P100, and indeed to captive primate knapped artefacts (Delagnes and Roche, 2005; Pelegrin, 2005; Schick and Toth, 2006). The importance of percussive activities involving both an active hammerstone and a passive anvil have also recently been highlighted in the human archaeological record at Olduvai (de la Torre et al., 2013; Mora and de la Torre, 2005), West Turkana (Harmand et al., 2015; Lewis and Harmand, 2016), and Gesher Benot Yaqov (Goren-Inbar et al., 2015, 2002). 
Research into percussive technology has focused on the Plio-Pleistocene archaeological record, particularly in East Africa, where percussive behaviours played an important role in the subsistence strategies of early hominins (de la Torre and Mora, 2005; Mora and de la Torre, 2005). To identify this type of behaviour, a number of studies have developed referential data sets that characterize the archaeological signature of percussive activities (Arroyo, 2015; Caruana et al., 2014; de la Torre et al., 2013). These studies have either experimentally replicated percussion on the same raw materials identified in the archaeological record (Arroyo, 2015; de la Torre et al., 2013), or quantified the wear patterns associated with intentional percussive activities verses natural taphonomic damage (Caruana et al., 2014). For example, de la Torre et al. (2013) found that experimental activities such as nut cracking, bipolar knapping, meat tenderizing and plant processing produced a range of use-damage on the passive hammer (anvil) involved in the behaviour. This damage included archaeologically identifiable detached pieces, corresponding with typical percussive anvil products identified in the archaeological record (De la Torre and Mora, 2005). More recently, the importance of primate percussive technology and behaviours for interpreting the hominin archaeological record has been highlighted using GIS analytical techniques on tools used in field experiments (Benito-Calvo et al, 2015) and by captive chimpanzees (Arroyo et al., 2016).

Beyond chimpanzees, recent research with other tool-using primates provides insights into the emergence of hominin flake technology. For example, wild bearded capuchin monkeys in Serra da Capivara National Park (SCNP), Brazil, intentionally strike quartz cobbles together, unintentionally producing numerous fully conchoidal flakes (Proffitt et al., 2016). These flakes, resulting from the only recorded behaviour where wild primates deliberately strike stone tools on other stones, exhibit the same range of technological attributes commonly identified in hominin flaked assemblages. The identification of such artefacts in the primate record has relevance to the suggestion that hominin flaked technology may have initially emerged as a by-product of percussive behaviour (McGrew, 1992). This combination of new information regarding the technology of hominin percussive material in the East African archaeological record, and the identification of truly flaked primate (capuchin) artefacts, reaffirms the importance of the $\mathrm{P} 100$ lithic assemblage as a potentially valuable comparative dataset for the characterisation and identification of percussive behaviour in the archaeological record.

Here, we present a complete technological analysis of the lithic material excavated from the P100 site. The combined technological, refit and microscopic analysis of this percussive material provides a finer grained characterisation of the archaeological signature of wild chimpanzee nut cracking behaviour than previously achieved. By renewing the analysis of the Panda 100 lithic material, this valuable primatological assemblage can be of further use to researchers in understanding the emergence of both West African chimpanzee and hominin percussive behaviour. 


\section{Materials and methods}

\subsection{The Panda 100 site}

153 The P100 site is located within the Taï Forest in the western region of the Ivory Coast (Figure 1A) and 154 lies between the confluence of two rainforest streams that frequently inundate the surrounding area. 155 Mercader et al (2002) addressed the degree of spatial and artefactual integrity of the lithic assemblage, 156 noting that all material was identified in low energy sedimentary contexts, consisting of non-stratified 157 clay, silt and sand sediments. Coupled with the presence of numerous nut shells and a high frequency 158 of artefacts $<20 \mathrm{~mm}$ ( $\mathrm{n}=374$ of 479 pieces; 78\%) in maximum dimension, these data suggest that post159 depositional fluvial transportation of the assemblage was not a significant factor (Mercader et al., 2002). 160 In addition, the vast majority of the lithic artefacts possess fresh fractured edges, with very little rounding of fractured surfaces, suggesting minimal fluvial effects.

P100 is in the immediate vicinity of a single Panda tree where chimpanzees were directly observed to crack nuts with stone tools. During the occupation of this site, from at least 1975, stone hammers were used in conjunction with wooden anvils, consisting of protruding tree roots. The site was eventually abandoned in 1996 (Boesch and Boesch, 1984a; Mercader et al., 2002) when the Panda tree died and fell to the ground. The immediate area is devoid of adequate raw material sources for use as hammerstones, suggesting that all tools were actively carried to the vicinity of the Panda tree.

Archaeological excavation at P100 covered $59 \mathrm{~m}^{2}$, excavated in arbitrary spits of $3 \mathrm{~cm}$, concentrating on the regions immediately surrounding four visible anvils. In addition, an excavation of the wider area was conducted to a depth of $5 \mathrm{~cm}$, resulting in the identification of two addition anvils. Fragmented lithic material was associated with all anvil areas and a total of 479 artefacts were recorded, consisting of four raw materials: granitoid, laterite, diorite, and quartzite. These were classified based on general morphology into hammer edges, cortical and non-cortical flakes, tabular products, angular shatter, amorphous shatter and microshatter $(<20 \mathrm{~mm})$ (Mercader et al., 2002). Of these artefact categories, Mercader et al. paid particular attention to the flakes, arguing that these shared similar dimensional, morphological and technological attributes to Oldowan flakes (Omo, Gona and Koobi Fora). They identified partially and non-cortical flakes, and a single example with a dihedral striking platform (Mercader et al., 2002). Seven refits (16 pieces) were also identified at two anvils, representing a maximum horizontal movement of stone pieces of between 0.05 and $1.60 \mathrm{~m}$. 
182 Figure 1. (A) Location map of Panda 100 (P100) site. (B) Updated excavation and refit map of P100 183 lithic assemblage (adapted from Mercader et al (2002) and updated with new digitised data from the current study)

185 There are currently five published radiocarbon dates for the Panda 100 site (Mercader et al., 2007) 186 (Table 1). These dates were obtained from excavations in 2003, which extended the P100 excavations into deeper and older sediments than those that contained the tools discussed in the present study. The 188 deeper sediments returned uncalibrated radiocarbon ages of 2330-4280 BP, which equate to 2182-4966 years BP when calibrated. These dates therefore do not reflect the age of the P100 artefacts reported in 2002 (Mercader et al., 2002) and re-analysed here. Instead, the lithic data presented here come from artefacts most likely deposited in the second half of the twentieth century, including during the time of observed use of the P100 sites by wild chimpanzees from 1979 to 1996.

Table 1. Uncalibrated and calibrated radiocarbon ages from the Panda 100 site (Mercader et al., 195 2007), calibrated using OxCal 4.2 and the IntCal13 curve

\begin{tabular}{lllll}
\hline Sample $\square$ & $\begin{array}{l}\boldsymbol{\delta} \text { 13C } \\
\text { \% }\end{array}$ & 14C age & $\begin{array}{l}\text { Years BP } \\
\mathbf{( 6 8 . 2 \% )} \square\end{array}$ & $\begin{array}{l}\text { Years BP } \\
\mathbf{( 9 5 . 4 \% )}\end{array}$ \\
\hline Beta-172916 & -27.6 & $2330 \pm 40$ & $2420-2311$ & $2485-2182$ \\
Beta-164876 & -27.9 & $2440 \pm 40$ & $2684-2364$ & $2705-2721$ \\
Beta-164877 & -27.2 & $2440 \pm 40$ & $2684-2364$ & $2705-2721$ \\
Beta-172913 & -26.8 & $3750 \pm 40$ & $4218-3999$ & $4235-3984$ \\
Beta-164879 & -25 & $4280 \pm 40$ & $4871-4827$ & $4966-4711$
\end{tabular}

a Sample depths below the site surface are not provided in the original publication

b $68.2 \%$ and $95.4 \%$ probability intervals

198

\subsection{Technological analysis}

200 For this study, all P100 lithic material was measured and weighed, with pieces $>20 \mathrm{~mm}$ subjected to a 201 full technological analysis. In the original report of the P100 lithic material (Mercader et al., 2002) a brief analysis of the lithic material included typological classifications and dimensions of the artefacts as well as the range of raw materials present. Since that time a number of technological analyses have been conducted on both hominin and primate percussive lithic assemblages. Of these de la Torre and Mora $(2005,2013)$ have outlined a comprehensive techno-typological classificatory scheme for the 
developed through the analysis of hominin passive anvils and their associated detached products, and the analysis presented here draws on these classification schemes in order to characterise the P100 lithic material. Mora and de la Torre (2005) set out five separate passive element percussive groups, based

210 on both the morphological location from which a fragment is derived and its technological 211 characteristics. These include edge products (Group 1.1), corner products (Group 1.2), elongated 212 detached pieces from the anvil faces (Group 2.1), angular chunks (Group 2.2), and detached pieces that 213 may resemble knapped flakes with a high degree of percussive damage (Group 2.3). Subsequently, 214 Arroyo (Arroyo, 2015; Arroyo and de la Torre, 2016) expanded on this classificatory system, to include typical hammerstone flakes (Group 3), resembling knapping hammerstone unintentional detachments which possess a convex ventral surface with no clear impact point, and angular fragments detached spontaneously from an inactive region of the hammer or anvil (Group 4). In addition to these

218 classifications, artefacts smaller than $20 \mathrm{~mm}$ in maximum dimensions that exhibited no clear percussive 219 damage were classified as small debris (Group 5).

\section{$221 \quad 3.3 \quad$ Refit analysis}

222 A total of 471 artefacts underwent 40 hours of refitting. All artefacts were subjected to refit analysis, 223 using a raw material grouping as well as coordinate grouping. Initially artefacts from each anvil were 224 grouped followed by the grouping of all artefacts of each raw material. The vertical distance between 225 refits may reflect a degree of time depth. As precise coordinates for each artefact are not available, the 226 only way to assess vertical refit distance is through the variation in spits for each refit. Mercader et al. 227 (2002) report that each spit was arbitrarily defined as $3 \mathrm{~cm}$ thick, with a total of six spits being excavated as well as material collected from the sub-surface.

229 An original refit study by Mercader et al. (2002) documented movement of artefacts at P100 over a 230 distance of 0.05-1.6 $\mathrm{m}$. To determine horizontal distance between refits, the original excavation hand 231 drawn artefact maps were digitised using ArcMap and georeferenced to an internally coherent 232 coordinate system. In most cases refitted pieces were correlated to drawn artefacts in the original notes, 233 however, in a few cases $(n=5)$ either no artefacts or a single artefact in the refit set could not be identified 234 in the original notes. To determine distance between refitted pieces, where possible, exact 235 measurements were taken using ArcMap, however, where no correlation with hand drawn notes was 236 possible distance was calculated by taking the measurements from the centre of associated grid references (we have distinguished between these two methods of measurement in Table 4). It is important to note that the distances reported in this study must be considered as minimum transportation distances, as hammerstone movement by chimpanzees is well documented by direct observation, and 240 may consist of numerous individual transport events (Boesch and Boesch, 1984a; Luncz et al., 2016). 
241 In addition to horizontal measurements, the vertical distance between refitted pieces was calculated from spit designations.

\subsection{Microscopic analysis}

245 All lithic artefacts $>20 \mathrm{~mm}$ in maximum dimension were macroscopically screened for evidence of 246 percussive damage. Potentially damaged areas were analysed using a low-powered magnification $247(<100 \mathrm{x})$ using a Leica S9APO stereo microscope equipped with a 1-8x objective lenses and a 10x 248 eyepiece. Microscopic photographs were taken using a 3.1Mp EC3 digital microscope camera. 249 Characterisation of use-wear damage followed the criteria of Adams et al. (Adams et al., 2006), which 250 has been successfully applied to other primate battered lithics (Arroyo, 2015; Arroyo and de la Torre, $2512016)$

\section{4. $\quad$ Results}

\subsection{Technological analysis}

$255 \quad$ 4.1.1 General frequencies

256 The available lithic assemblage from Panda 100 consists of 473 artefacts, from five raw materials 257 including granitoid $(n=376,76.5 \%)$, laterite $(n=80,17.1 \%)$, diorite $(n=9,1.7 \%)$, quartzite $(n=6,1.3 \%)$ 258 and weathered clast $(\mathrm{n}=2,0.4 \%)$. The two pieces of weathered clast have been omitted from the 259 following technological analysis as they are not mentioned in the original P100 report, may have entered 260 the archaeological record through natural processes, and are not likely to have been utilised by 261 chimpanzees as nut cracking hammerstones. In addition to this, all feldspar artefacts (originally reported 262 as coming solely from Anvil 4), a single quartzite and a single diorite piece reported by Mercader et al. 263 (2002) were not identified in this study, resulting in a mis-match of eight artefacts (1.67\%).

264 The majority of the lithic assemblage is small debris $(n=364,77.3 \%)$, angular chunks $(n=34,7.2 \%)$ 265 and angular fragments $(\mathrm{n}=25,5.3 \%)$. Techno-typological categories more frequently associated with 266 percussive behaviour in the archaeological record are represented in low frequencies, such as corner 267 fragments $(n=30,6.4 \%)$, edge fragments $(n=14,3 \%)$, and typical hammerstone flakes $(n=3,0.6 \%)$. 268 Only one piece $(0.2 \%)$ in the assemblage possesses a morphological similarity to detached flakes (Table 2) (Supplementary Material 1). 
272 Table 2. Absolute and relative frequency of technological artefact types for each raw material at 273 Panda 100

\begin{tabular}{|c|c|c|c|c|c|c|c|c|c|c|}
\hline & \multicolumn{2}{|c|}{ Diorite } & \multicolumn{2}{|c|}{ Granite } & \multicolumn{2}{|c|}{ Laterite } & \multicolumn{2}{|c|}{ Quartzite } & \multicolumn{2}{|c|}{ Total Assemblage } \\
\hline & $\mathbf{n}$ & $\%$ & n & $\%$ & $\mathbf{n}$ & $\%$ & $\mathbf{n}$ & $\%$ & $\mathbf{n}$ & $\%$ \\
\hline Group 1.1 & 1 & 11.1 & 13 & 3.5 & 0 & 0.0 & 0 & 0.0 & 14 & 3.0 \\
\hline Group 1.2 & 3 & 33.3 & 25 & 6.6 & 1 & 1.3 & 0 & 0.0 & 29 & 6.2 \\
\hline Group 2.1 & 0 & 0.0 & 1 & 0.3 & 0 & 0.0 & 1 & 16.7 & 2 & 0.4 \\
\hline Group 2.2 & 0 & 0.0 & 26 & 6.9 & 7 & 8.8 & 0 & 0.0 & 33 & 7.0 \\
\hline Group 2.3 & 1 & 11.1 & 0 & 0.0 & 0 & 0.0 & 0 & 0.0 & 1 & 0.2 \\
\hline Group 3 & 3 & 33.3 & 0 & 0.0 & 0 & 0.0 & 0 & 0.0 & 3 & 0.6 \\
\hline Group 4 & 0 & 0.0 & 18 & 4.8 & 7 & 8.8 & 0 & 0.0 & 25 & 5.3 \\
\hline Group 5 & 1 & 11.1 & 293 & 77.9 & 65 & 81.3 & 5 & 83.3 & 364 & 77.3 \\
\hline Total & 9 & & 376 & & 80 & & 6 & & 471 & \\
\hline
\end{tabular}




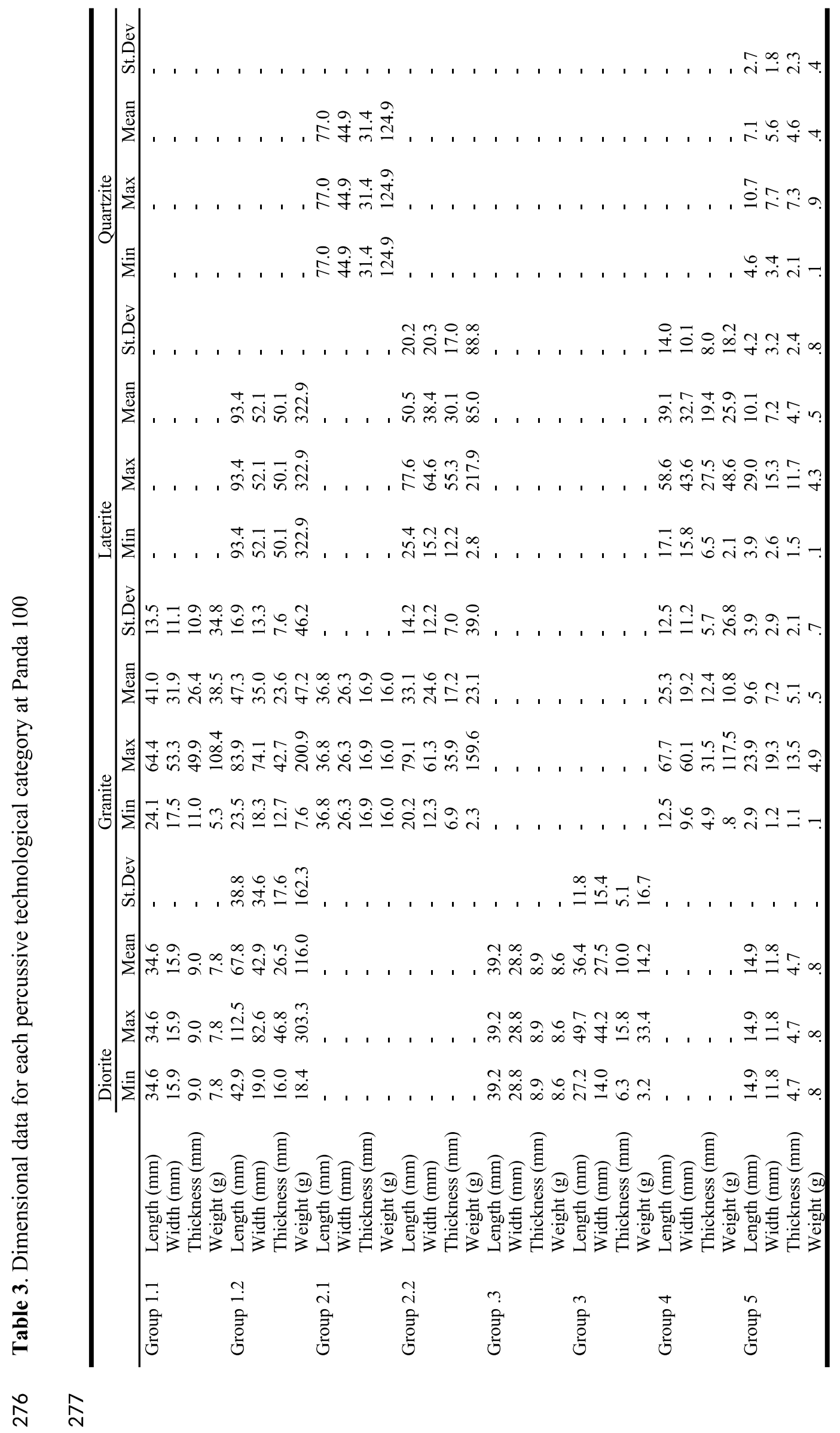


279 Six quartzite artefacts were recovered from the P100 excavations, two from the vicinity of Anvil 4, two 280 from Anvil 3 and one each from Anvils 5 and 6. Small debris makes up the majority of this sample $281(\mathrm{n}=5,83.3 \%)$, with a mean length, width and thickness of $7.1 \times 5.6 \times 4.6 \mathrm{~mm}$ and a mean weight of $2820.4 \mathrm{~g}$ (Table 3). The small debris does not show evidence of percussive damage, and as such may 283 represent a background natural 'noise' of small quartzite fragments.

284 A single tabular quartzite edge fragment was also identified, measuring $77 \times 44.9 \times 31.4 \mathrm{~mm}$ and 285 weighing $124.9 \mathrm{~g}$ (Table 3). This edge piece possesses a single impact point located on the intersection 286 of a cortical horizontal plane and a newly fractured vertical plane. The fractured pane is clearly non287 cortical and possesses sharp and fresh edges, indicating it as a relatively recent breakage. Apart from 288 the impact point that resulted in the fragmenting of the hammerstone, no repeated percussion marks are 289 evident on either horizontal planes of the edge fragment. However, it has been shown that very little 290 macro and microscopic damage develops on quartzite during nut cracking activities (de la Torre et al., 291 2013), which may go some way to explaining the lack of visible percussive damage, coupled with the 292 fact that softer organic anvils were used at this site. The thickness of this piece $(31.4 \mathrm{~mm})$ suggests that 293 the original hammerstone was probably relatively thin.

\section{$\underline{4.1 .3 \quad \text { Diorite assemblage }}$}

296 Eight diorite artefacts have a total weight of 407.7g. Almost all were found around Anvil 4 ( $\mathrm{n}=7$, $29787.5 \%)$, with a single fragment from Anvil 1. The diorite artefacts include corner $(n=3,33.3 \%)$ and 298 edge fragments $(n=1,11.1 \%)$, typical hammerstone flakes (Group 3) ( $n=3,33.3 \%)$, a conchoidally 299 fractured piece or positive base $(\mathrm{n}=1,11.1 \%)$, and a single piece of small debris (11.1\%). Compared to 300 the dominant granitoid raw material at P100, the diorite is relatively homogenous in structure, with no 301 visible internal fissures or fractures and a fine-grained texture. The higher quality of this raw material 302 helps explain the high percentages of fractured diorite pieces as opposed to angular chunks and small 303 debris.

304 The single diorite edge fragment measures $34.6 \times 15.9 \times 9 \mathrm{~mm}$ (maximum dimensions) and weighs $3057.8 \mathrm{~g}$ (Table 3), however when orientated technologically this fragment is relatively wide and thin in 306 morphology $(15.6 \times 33.8 \mathrm{~mm})$. All diorite corner fragments retain a portion of the active percussive 307 plane, indicating that this surface was flat and cortical (Figure 2B). In addition, Refit Set 2 (see below) 308 is a distal fragmentation of a corner piece that retains both the active percussive plane and the opposed 309 plane (Plane A2) suggesting that the diorite hammer had a tabular morphology. Coupled with the 310 presence of typical hammerstone flakes (see below), two distinct morphologies of diorite hammerstone were used, tabular blocks and rounded cobbles. The majority of diorite percussive fragments possess a 
cortical dorsal surface, with only a single example possessing a fully non-cortical dorsal surface. This finding suggests that repeated fragmentation of individual diorite hammerstones was a rare occurrence. Of particular interest amongst the diorite artefacts is the singular piece that resembles, morphologically, a percussive flake (Figure 3). This piece possesses a clear non-cortical striking platform, although no distinct impact points are visible. The striking platform is relatively large, measuring $7.5 \times 16.5 \mathrm{~mm}$ with a flat morphology. The flake possesses clearly delimitated dorsal and ventral surfaces and a diffuse bulb of percussion. The dorsal surface is $>50 \%$ cortical, however it also retains evidence of three previous unidirectional, small dorsal removals. However, it is impossible to identify whether these removals were flake detachments or merely evidence of previous fragmentation.

Three of the diorite fragments can be considered stereotypical hammerstone detachments, two complete and one fragmented (Figure 3). These possess convex cortical dorsal surfaces with highly concave ventral surfaces. No clear impact point is present and none possess an area that could be considered a striking platform.

Insert Figure 2

Figure 2. Examples of detached percussive products from lithic hammerstones at P100. (A) Granitoid and diorite edge pieces (Group 1.1). (B) Granitoid and diorite corner fragments (Group 1.2). (C) Examples of granitoid and laterite small debris $(<20 \mathrm{~mm})($ Group 5$)($ scales $=5 \mathrm{~cm})$.

Insert Figure 3

Figure 3. Examples of detached percussive artefacts from lithic hammerstones at P100. (A) Detached diorite conchoidal flake (Group 2.3). (B) Detached diorite typical hammerstone flakes (Group 3) (scales $=5 \mathrm{~cm})$

\subsubsection{Laterite assemblage}

80 laterite fragments, weighting a total of $1131.9 \mathrm{~g}$, were found at P100. Most of these are either small debris ( $\mathrm{n}=65,81.3 \%)$ or angular chunks and fragments (Group 2.2 and Group 4) ( $\mathrm{n}=14,17.6 \%)$, along with a corner fragment $(\mathrm{n}=1,1.3 \%)$, with no clear evidence of percussive behaviour other than their fragmented state. Of note, the single corner fragment and an angular chunk were found to refit (Refit Set 9), which provides the only potential evidence of percussive behaviour for this material and is described in detail below. A second refit (Refit Set 1) records the fracturing of a small laterite cobble, which was likely not used for successful Panda nut percussion, however, may have been used by a 
juvenile (Boesch and Boesch, 1984b). The lack of macroscopic percussive damage on the majority of laterite artefacts does not in itself necessarily preclude laterite being used in percussive behaviour. Their close association with organic anvils and nut shells, coupled with the fact that chimpanzees in Taï have been known to use this raw material, all increase the possibility of a percussive origin for these artefacts. However, based purely on percussive damage evidence in the P100 archaeological context this raw material would not be attributed to percussive behaviour. These laterite pieces represent the fragmentation or splitting of relatively small cobbles, and they do not share the same morphology as a detached corner fragments from a larger tabular block, as is seen with the diorite hammerstones.

\subsubsection{Granitoid assemblage}

The 376 granitoid artefacts make up the majority of the P100 lithic assemblage. The P100 granitoid is coarse-grained, with a high quartzite composition in the form of individual crystals held in a fine grained matrix. Its internal structure has major fractures and fissures directly associated with regions of interior foliation that often grade into a highly irregular, coarse-grained internal structure.

The majority of the granitoid pieces are small debris ( $\mathrm{n}=293,77.9 \%)$ (Figure 2) with mean dimensions of $9.6 \times 7.2 \times 5.1 \mathrm{~mm}$ and a mean weight of $0.5 \mathrm{~g}$ (Table 3 ). The second most prevalent artefact types are angular chunks and angular fragments (including groups 2.1, 2.2 and group 4) (n=45, 12\%); these show no evidence of percussive damage but their highly fragmented state suggests a percussive origin. Of the identifiable percussive techno-morphological categories, corner fragments are the most frequent $(n=25,6.6 \%)$, followed by edge fragments $(n=13,3.5 \%)$. The presence of these technological morphotypes within the assemblage represents archaeologically visible evidence of percussive behaviour, and in a number of cases these artefacts possess direct evidence of percussive impact.

The corner fragments possess mean maximum measurements of $47.3 \times 35 \times 23.6 \mathrm{~mm}$ and a mean weight of $47.2 \mathrm{~g}$ (Table 3). When orientated technologically, however, they possess a mean length and width of $35.2 \times 37.8 \mathrm{~mm}$, presenting a roughly cuboid morphology. The preserved portion of the active percussive plane (platform) was identifiable in $92 \%(n=23)$ of all corner fragments. The majority possessed cortical platforms ( $\mathrm{n}=19,76 \%$ ), however, a small number also possessed fully non-cortical platforms ( $\mathrm{n}=3,12 \%)$. These platforms were relatively large (average length and width: $25.3 \times 17.6 \mathrm{~mm}$ ) and flat. Granitoid corner fragments possess relatively large external (mean $=122.7$ degrees) and interior (mean=102.5 degrees) platform angles, highlighting the forceful nature of their detachment. Corner fragments possessed either flat $(n=13,52 \%)$ or irregular $(n=10,40 \%)$ ventral surface morphologies, with only a very small proportion possessing concave morphologies. Dorsal surfaces were primarily $>50 \%$ cortical ( $>50-100 \%$ cortex coverage) $(n=21,84 \%)$, with only a few examples possessing $<50 \%$ cortex coverage $(n=4,16 \%)$ (Figure 2$)$. Only $12 \%(n=3)$ possessed dorsal surface detachments, suggesting that corner fragment detachment often occurred as an initial breakage of the 
hammerstone. These fragments also typically possessed either a triangular $(n=14,56 \%)$ or trapezoid $(\mathrm{n}=9,36 \%)$ transversal cross section.

Granitoid edge fragments possess mean maximum measurements of 41 × 31.9 × $26.4 \mathrm{~mm}$ and a mean weight of $38.5 \mathrm{~g}$ (Table 3). However, when technologically orientated they measure on average $28.6 \mathrm{x}$ $32.5 \mathrm{~mm}$, making them relatively wide and short in morphology. Almost all possess a fully cortical $(\mathrm{n}=12,92.3 \%)$ striking platform or the remnants of the active percussive plane, with only one example (7.7\%) possessing a non-cortical platform. The platforms are relatively substantial and rectilinear in morphology, possessing a mean length and width of 28.2 x $21.4 \mathrm{~mm}$. Edge fragments possessed a mean exterior platform angle of 117.7 degrees and a mean interior platform angle of 98.5 degrees. The dorsal surfaces of these fragments, representing the outer plane of the hammerstone, possess either triangular $(n=5,38.5 \%)$ or trapezoid $(n=8,61.5 \%)$ transversal cross section, and are rarely fully cortical $(n=1$, $7.7 \%)$ or non-cortical $(n=1,7.7 \%)$, possessing either $>50 \%(n=7,53.8 \%)$ or $<50 \%$ cortex coverage $(n=4,30.8 \%)$ (Figure 2). The presence of non-cortical regions on the dorsal surface, coupled with the identification of single dorsal extractions on four (30.8\%) pieces, suggests that there is a repeated nature to the edge fragmentation of the P100 granitoid hammerstones.

\subsection{Refit analysis}

The original Panda 100 publication reported seven refit sets, totalling 16 refitted artefacts, and comprising three raw materials: granitoid, laterite and diorite (Mercader et al., 2002). These refits revealed a maximum horizontal movement of $1.6 \mathrm{~m}$ and were identified at two of the six excavated anvil locations, Anvils 1 and 4 . The original report did not identify the artefacts that contributed to these refit sets, with only one refit being identified via an illustration (Mercader et al., 2002 Fig. 2E). No technological analysis of the refitted material was presented.

Our updated refit analysis of the Panda 100 lithic assemblage substantially increases the number of refits, and provides a detailed technological analysis of each refit set (Supplementary Material 2). A total of 35 artefacts were refitted ( $7.43 \%$ of the entire assemblage), increasing the total number of refit sets from seven to twelve (Table 4). Other than the illustrated example in Mercader et al. (2002), we do not know which of the refits identified in this study overlap with the ones described in the original report. The increased number of refit sets does, however, permit a number of new insights. First, refits are now represented at four separate anvil locations: while the majority are located within the vicinity of Anvil 4, refits are also identified at Anvils 1, 2, and 5. Second, three of the refit sets represent movement of hammerstones between anvil locations, with refitted fragments being identified between Anvil 4 and Anvils 1 and 5 as well as between Anvils 2 and 5. 
412 The refits illustrate how hammerstones fragment during Panda nut cracking behaviour (Figures 4-8).

413 The majority of the large fractures result from detachment of corner and edge fragments, often in

414 tandem, with these pieces being detached consecutively or simultaneously. It is, however, possible to

415 identify two primary fragmentation sequences within the P100 refits. The first sequence consists of

416 small, non-invasive removals that detach a small portion of the intersection between the horizontal

417 active plane and the vertical planes. This type of hammerstone fragmentation results in an increasingly

418 rounded morphology of the hammerstone edges. The second fragmentation sequence is a more invasive

419 'slicing' of the hammerstone, whereby a large corner or edge fragment that retains remnants of both the

420 active percussive surface, as well as the opposing plane of the hammerstone, is detached. This process

421 results in a rapid loss of the volume of the hammerstone. Both of these fragmentation sequences are

422 represented within the refit assemblage independently, as well as associated with each other in single

423 refits sets. Furthermore, corner fragments appear to result from initial fragmentation of the

424 hammerstone, followed either simultaneously or soon afterwards by detachments of short and wide

425 edge fragments. 
Table 4. Refits identified in the current study of the Panda 100 lithic assemblage

\begin{tabular}{|c|c|c|c|c|c|c|c|c|}
\hline $\begin{array}{l}\text { Refit } \\
\text { Set }\end{array}$ & $\begin{array}{l}\text { Raw } \\
\text { Material }\end{array}$ & $\begin{array}{l}\text { Number } \\
\text { Pieces }\end{array}$ & of & $\begin{array}{l}\text { Piece } \\
\text { Numbers }\end{array}$ & $\begin{array}{l}\text { Technological } \\
\text { Categories }\end{array}$ & $\begin{array}{l}\text { Grid } \\
\text { Reference }\end{array}$ & $\begin{array}{l}\text { Total } \\
\text { Horizontal } \\
\text { Distance }(\mathrm{m})\end{array}$ & $\begin{array}{l}\text { Spit } \\
\text { Range }\end{array}$ \\
\hline 1 & Laterite & 2 & & $\begin{array}{l}\text { P15 } \\
\text { P16 }\end{array}$ & $\begin{array}{l}2.2 \\
2.2\end{array}$ & $\begin{array}{l}\text { R9 } \\
\text { R9 }\end{array}$ & 0.21 & $1-2$ \\
\hline 2 & Diorite & 2 & & $\begin{array}{c}\text { P25 } \\
\text { P7 }\end{array}$ & $\begin{array}{l}1.2 \\
1.1\end{array}$ & $\begin{array}{l}\mathrm{S} 10 \\
\mathrm{R} 11\end{array}$ & $1-2 *$ & $0-1$ \\
\hline 3 & Granitoid & 4 & & $\begin{array}{l}\text { P28 } \\
\text { P29 } \\
\text { P39 } \\
\text { P47 }\end{array}$ & $\begin{array}{l}1.2 \\
1.1 \\
1.1 \\
1.2\end{array}$ & $\begin{array}{l}\text { S10 } \\
\text { S10 } \\
\text { K7 } \\
\text { K8 }\end{array}$ & $9.54^{1}$ & $1-2$ \\
\hline 4 & Granitoid & 2 & & $\begin{array}{l}\text { P40 } \\
\text { P53 }\end{array}$ & $\begin{array}{l}1.2 \\
1.1\end{array}$ & $\begin{array}{l}\text { K7 } \\
\text { K8 }\end{array}$ & $1-2 *$ & 3 \\
\hline 5 & Granitoid & 2 & & $\begin{array}{l}\text { P18 } \\
\text { P42 }\end{array}$ & $\begin{array}{l}2.2 \\
2.2\end{array}$ & $\begin{array}{l}\text { S10 } \\
\text { R11 }\end{array}$ & 1.27 & $0-1$ \\
\hline 6 & Granitoid & 3 & & $\begin{array}{l}\text { P48 } \\
\text { P52 } \\
\text { P97 }\end{array}$ & $\begin{array}{l}1.2 \\
1.2 \\
2.2\end{array}$ & $\begin{array}{l}\mathrm{T} 10 \\
\mathrm{~T} 10 \\
\mathrm{~T} 10\end{array}$ & 0.26 & 0 \\
\hline 7 & Granitoid & 4 & & $\begin{array}{l}\mathrm{P} 12 \\
\mathrm{P} 30 \\
\mathrm{P} 32 \\
\mathrm{P} 45\end{array}$ & $\begin{array}{l}1.2 \\
1.1 \\
1.2 \\
1.2\end{array}$ & $\begin{array}{c}\mathrm{S} 10 \\
\mathrm{~T} 10 \\
? \\
\mathrm{~S} 10\end{array}$ & 1.34 & $0-1$ \\
\hline 8 & Granitoid & 2 & & $\begin{array}{l}\text { P49 } \\
\text { P51 }\end{array}$ & $\begin{array}{l}1.2 \\
1.1\end{array}$ & $\begin{array}{l}\mathrm{T} 10 \\
\mathrm{~S} 10\end{array}$ & 0.83 & 0 \\
\hline 9 & Laterite & 2 & & $\begin{array}{l}\text { P21 } \\
\text { P33 }\end{array}$ & $\begin{array}{l}1.2 \\
2.2\end{array}$ & $\begin{array}{l}\mathrm{N} 6 \\
\mathrm{~L} 23\end{array}$ & $17.12^{1}$ & 1 \\
\hline 10 & Granitoid & 5 & & $\begin{array}{c}\text { P6 } \\
\text { P9 } \\
\text { P22 } \\
\text { P27 } \\
\text { P56 }\end{array}$ & $\begin{array}{l}1.1 \\
1.2 \\
2.2 \\
1.2 \\
4\end{array}$ & $\begin{array}{l}\mathrm{R} 10 \\
\mathrm{~K} 24 \\
\mathrm{~T} 10 \\
\mathrm{R} 10 \\
\mathrm{~S} 10\end{array}$ & $16.59^{1}$ & $0-1$ \\
\hline 11 & Granitoid & 2 & & $\begin{array}{l}\mathrm{P} 1 \\
\mathrm{P} 11\end{array}$ & $\begin{array}{l}1.2 \\
1.2\end{array}$ & $\begin{array}{c}\text { T10 } \\
?\end{array}$ & - & - \\
\hline 12 & Granitoid & 5 & & $\begin{array}{l}\text { P24 } \\
\text { P41 } \\
\text { P58 } \\
\text { P65 } \\
\text { P88 }\end{array}$ & $\begin{array}{c}1.1 \\
1.1 \\
2.2 \\
2.2 \\
4\end{array}$ & $\begin{array}{l}\text { L8 } \\
\text { K8 } \\
\text { K8 } \\
\text { K8 } \\
\text { K8 }\end{array}$ & 1.49 & $1-3$ \\
\hline
\end{tabular}

$445{ }^{1}$ No direct measurement possible for a single piece in refit set, distance was estimated based on grid 446 reference 
452 Figure 4. Refit Sets 1 and 2 from Panda 100. (A) Refit Set 1: Two laterite angular chunks. (B) Refit

453 Set 2: Distally fractured, detached corner fragment of a diorite hammerstone (scales $=5 \mathrm{~cm}$ )

\section{Insert Figure 5}

456 Figure 5. Refit Sets 3 and 4 from Panda 100. (A) Refit Set 3: Four granitoid fragments, two edge 457 fragments and two corner fragments. (B) Refit Set 4: Two granitoid fragments representing a corner 458 region of a hammerstone $($ scales $=5 \mathrm{~cm})$

Insert Figure 6

461 Figure 6. Refit Sets 5, 6 and 7 from Panda 100. (A) Refit Set 5: Two angular chunks representing the 462 edge of a granitoid hammerstone. (B) Refit Set 6: Two corner fragments and one angular chunk representing corner detachment of a granitoid hammer. (C) Refit Set 7: Corner refit of a tabular granitoid hammerstone consisting of three corner fragments and one edge fragment (scales $=5 \mathrm{~cm}$ )

Insert Figure 7

467 Figure 7. Refit Sets 8 and 9 from Panda 100. (A) Refit Set 8: Edge fragment of a granitoid hammerstone 468 consisting of one corner fragment and one edge fragment. (B) Refit Set 9: Minor fragmentation of a laterite cobble $($ scales $=5 \mathrm{~cm})$

470

$471 \quad$ Insert Figure 8

472 Figure 8. Refit Sets 10, 11, and 12 from Panda 100. (A) Refit Set 10: Five granitoid fragments (three 473 corner fragments, two angular chunks) representing extensive fragmentation of a large hammerstone. 474 (B) Refit Set 12: Five granitoid fragments (two edge fragments, three angular chunks) of a larger 475 hammerstone corner region. (C) Refit Set 11: Edge fragment of a granitoid hammerstone consisting of 476 one angular chunk and one edge fragment (scales $=5 \mathrm{~cm})$ 
478 Just under half of the P100 refit sets ( $\mathrm{n}=5,41 \%)$ are formed of pieces from two neighbouring meter 479 squares at the site, and therefore represent a horizontal movement of 1-2 $\mathrm{m}$. A smaller number come 480 from the fragmentation of a hammerstone within a single meter $(n=3,25 \%)$, or a horizontal movement 481 of $<1 \mathrm{~m}$. However, three (25\%) refit sets record more substantial horizontal movement and inter-anvil 482 transportation of hammerstones. In one instance, the hammerstone was transported $9.54 \mathrm{~m}$ between 483 successive breakage events, and in two instances refitting pieces were found 16-17 metres apart (Figure 4849 and Figure 10) (Supplementary Material 3).

485 Four refits (33\%) record hammerstones that were likely broken at a single point in time, with examples 486 found within the subsurface level and Spits 1 and 3 respectively. Another four refits were found between 487 the subsurface level and spit 1, with a further two (17\%) examples being identified between Spits 1 and 4882 , representing a maximum vertical movement of $6 \mathrm{~cm}$. A single refit $(8 \%)$ was formed of pieces found 489 in Spits 1-3, representing a maximum vertical movement of $9 \mathrm{~cm}$. This vertical movement suggests a 490 degree of reuse of hammerstones over time, with previously used hammerstones being actively removed 491 from the developing archaeological record and subsequently fragmented.

\section{Insert Figure 9}

494 Figure 9. Spatial map of Panda 100 excavations showing refit sets

\section{Insert Figure 10}

Figure 10. Mapped artefacts and refit sets at Panda 100, separated by anvil and spit 
510 Microscopic damage was identified on 13 fragmented pieces (Table 5). Most of these were corner 511 fragments $(n=9,69.2 \%)$, however, edge fragments $(n=4,30.8 \%)$ are also represented (Table 5).

512 Granitoid is the prevalent raw material, making up eight of the 13 pieces with visible percussive 513 damage, whereas only a single diorite artefact possessed visible percussive wear.

515 Table 5. Percussive damage identified on lithic artefacts from P100

\begin{tabular}{|c|c|c|c|}
\hline $\begin{array}{l}\text { Piece } \\
\text { Number }\end{array}$ & $\begin{array}{l}\text { Raw } \\
\text { Material }\end{array}$ & $\begin{array}{l}\text { Artefact } \\
\text { Category }\end{array}$ & Microscopic Percussive Damage \\
\hline P13 & Granitoid & 1.2 & $\begin{array}{l}\text { Crushing and levelling of individual crystals. The development of a } \\
\text { frosted and irregular surface morphology. }\end{array}$ \\
\hline P14 & Diorite & 1.2 & Isolated crushing and fracturing of individual quartz crystals \\
\hline P31 & Granitoid & 1.2 & $\begin{array}{l}\text { Large area of intense crushing of quartz crystals and matrix. } \\
\text { Development of large step scars and the detachment of individual } \\
\text { crystals. }\end{array}$ \\
\hline P37 & Granitoid & 1.2 & $\begin{array}{l}\text { Small areas of crushing, and frosting of quartz crystals. Small step } \\
\text { fractures within the crushed areas }\end{array}$ \\
\hline P38 & Granitoid & 1.2 & $\begin{array}{l}\text { Crushing of quartz crystals and surrounding matrix. Detachment of } \\
\text { individual crystals and the development of step scars. }\end{array}$ \\
\hline P48 & Granitoid & 1.2 & $\begin{array}{l}\text { V-shaped impact point in close association with intense crushing of } \\
\text { quartz crystals. }\end{array}$ \\
\hline P70 & Granitoid & 1.1 & $\begin{array}{l}\text { V-shaped impact point. Intense crushing of quartz crystals and light } \\
\text { crushing of matrix. Levelling of quartz crystals, resulting in an } \\
\text { irregular surface morphology. }\end{array}$ \\
\hline P80 & Granitoid & 1.2 & $\begin{array}{l}\text { V-shaped impact point, associated with an area of crushing and } \\
\text { levelling of quartz crystals. Detachment of individual crystals from } \\
\text { the matrix, and the development of small step scars. }\end{array}$ \\
\hline P91 & Granitoid & 1.2 & $\begin{array}{l}\text { V-shaped impact points, associated with intense crushing of quartz } \\
\text { crystals and matrix. Small step fractures. }\end{array}$ \\
\hline P41 & Granitoid & 1.1 & Small area of crushed quartz crystals and matrix \\
\hline $\mathrm{P} 24$ & Granitoid & 1.1 & Isolated area quartz crushing and slight pitting of the surface \\
\hline P39 & Granitoid & 1.1 & Small area of crushed quartz crystals and matrix \\
\hline P47 & Granitoid & 1.2 & Small area of crushed quartz crystals and matrix \\
\hline $\mathrm{P} 25$ & Diorite & 1.2 & No identifiable percussive damage \\
\hline
\end{tabular}


517 Undamaged cortical granitoid surfaces are light brown with frequent, large, intact quartz crystals. The 518 natural granitoid surface morphology is either flat and levelled (with the quartz crystals showing worn 519 dulled surfaces) or, conversely, highly irregular (with protruding quartz crystals representing high 520 points on the surface). Percussive damage on granitoid hammerstone fragments is generally sparsely 521 located on the active percussive surface. The impacts are either located towards the centre of the 522 percussive plane or immediately on the edge where the percussive plane intersects one or more vertical 523 outer planes.

524 At a macroscopic level, percussive damage can be identified as a differentiation in colour when 525 compared to the unaltered cortical surface. At a microscopic level, percussive damage on these pieces 526 is characterised by crushing of individual grains, resulting in a compacted or compressed morphology located around a single impact point. This crushing and compaction results in a discolouration or frosting of the cortical surface to a distinct white. When impacts are located close to the edge they present a characteristic V-shape in plan, whereas, when located in the centre of the active plane on a relatively flat surface, they are characterised by an irregular plan shape. When located along an intersecting edge impacts may also be associated with either a single large step-terminating removal or a series of smaller crushed step fractures, where individual quartz crystals have either detached or fragmented. Whole quartz crystals may be detached from the granitoid matrix, leaving behind characteristic, deep depressions surrounded by an area of crushed and compacted matrix. These characteristics either occur individually or as combinations, and appear to be influenced by the density of quartz crystals within the granatoid matrix (Figure 11 and Figure 12).

Percussive damage on the single diorite artefact is superficial and only identifiable through macroscopic visual inspection by a slight depression and roughening of the cortical surface. Under the microscope, few identifiable characteristics can be clearly contrasted to the non-damaged cortical surfaces. Two small impact points and areas of crushing of the quartz crystals can be identified within the wider depressed area, however, these are not clearly related to percussive damage.

The issue of identifying percussive damage on diorite fragments at P100 is further complicated by the

543 larger corner fragment from Refit Set 2. Originally illustrated in Mercader et al (2002, Fig. 2E), this 544 piece possesses a small visible depression on its horizontal active plane (Plane A) measuring $26 \mathrm{x}$ $54515 \mathrm{~mm}$ in maximum dimensions. This has been interpreted as pitting (Mercader et al, 2002), however, 546 it is a natural undulation of the cortical surface. The lack of significant microscopic percussive traces 547 within the depressed region of the active plane indicates that this area was not formed through active 548 use. This is not to suggest that this artefact, and indeed the associated refit set, is not derived through 549 chimpanzee percussive action, only that the previously identified pitted feature is a natural depression within the surface morphology of the hammerstone (Figure 12). 


\section{Insert Figure 11}

554 Figure 11. Microscopic damage on percussive artefacts at Panda 100. (A) Granitoid corner fragment 555 (Group 1.2) with clear percussive damage. 1 and 2: Cortical, undamaged areas, showing intact quartz 556 crystals and flat smooth surface (scales $=500 \mu \mathrm{m}$ and $1000 \mu \mathrm{m}$ ). 3 and 4: Impact point showing 557 significant crushing and development of small steps along with detachment of quartz crystals ( scales $=$ $558500 \mu \mathrm{m}$ and $1000 \mu \mathrm{m}$ ). (B) Granitoid edge fragment (Group 1.1). 1: Undamaged cortical surface (scale $559=500 \mu \mathrm{m}) .2,3$ and $4: \mathrm{V}$-shaped impact points along the edge and interior of the percussive surface $560 \quad($ scales $=3000 \mu \mathrm{m}, 3000 \mu \mathrm{m}$ and $500 \mu \mathrm{m})$

\section{Insert Figure 12}

564 Figure 12. Microscopic damage of percussive artefacts at Panda 100. (A) Granitoid corner fragment 565 with clear percussive damage. 1: Cortical, undamaged surface (scale $=500 \mu \mathrm{m}) .2$ : V-shaped impact 566 point (scale $1000 \mu \mathrm{m}) .3$ : Crushing and step fractures associated with impact point (scale $=3000 \mu \mathrm{m})$. $5674 .:$ Impact point showing significant crushing of quartz crystals and matrix (scale $=1000 \mu \mathrm{m})$. (B) 568 Diorite corner fragment with possible pitted surface. 1 and 2: Cortical, undamaged surfaces preserving 569 intact crystals and matrix. 3 and 4: Undamaged surface from within the pitted surface, showing intact crystals and matrix (scale $=2000 \mu \mathrm{m})$.

\section{Discussion and conclusions}

573 Panda 100 was the first site to be archaeologically excavated to recover tool non-hominin tools.

574 However, the site has much to offer beyond its historical significance. It provides the highest resolution data available on how non-human animals create an archaeologically durable assemblage, giving new insights into how wild chimpanzee stone tools break and move during their use under natural conditions. The P100 artefacts conclusively demonstrate that there is a disconnect between the stone pieces left at

578 Panda nut-cracking sites and the actual hammers used by chimpanzees to crack nuts. The former are 579 fragmentary and small, the latter are large and battered. P100 therefore preserves evidence for an 580 important behavioural observation made at Taï, namely that hammerstones are routinely removed from 581 a site when a Panda tree becomes unproductive or dies. The P100 archaeological record has a preservation bias against actual tools, and towards stone pieces that could not in themselves ever be used to crack Panda nuts. Given that the evolution of chimpanzee stone technology likely encompasses at least tens of thousands of years [Add Haslam 2014 American Journal of Primatology here], with tool 
use potentially reaching into the millions of years (Panger et al., 2003), the correct interpretation of partial behavioural evidence at sites like P100 is critical for reconstructing that long-term record.

The raw materials excavated at the P100 site - granitoid, laterite, diorite and quartzite - accurately reflect the materials that primatologists have observed chimpanzees using for Panda processing in the Taï Forest (Boesch and Boesch, 1983). Other than laterite, these stones do not occur naturally in the immediate vicinity of the site, demonstrating that they were transported by chimpanzees. This kind of transport, essentially provisioning the Panda tree while it fruits, has also been well documented at Taï (Boesch and Boesch, 1984a; Luncz et al., 2016). In themselves, therefore, the fragmented P100 artefacts permit reconstruction of such fundamental behaviour as material selection and tool transport. From a primate archaeological perspective this is important as it allows the reconstruction (albeit at a low resolution) of primate behaviour in antiquity. In addition, GIS mapping of artefacts to their grid reference shows that the highest concentrations of material are found within the immediate vicinity $(<1$ m) of anvils (Figure 13). If the aim is to maximise recovery of artefacts, future West African chimpanzee archaeological excavations may therefore wish to concentrate on areas around anvils.

\section{Insert Figure 13}

Figure 13. Density maps of artefacts at Panda 100, separated by anvil location

Our technological analysis of the P100 artefacts is the most detailed yet performed for a wild chimpanzee lithic assemblage. It allows us to describe and interpret details of the unintentional reduction of stone tools by chimpanzee nut-cracking at a high resolution. This analysis found that two main fragmentation sequences dominate at P100, which may occur either independently, or concurrently. First, protruding corner regions of a hammerstone are removed through either direct impact or initiation of internal fracture planes. From behavioural observations, we know that such impacts are not deliberately aimed at the tool margins, but instead represent mis-hits or incidental blows, such as when the hammer contacts the anvil during nut-cracking (Arroyo et al., 2016). Once corner elements are removed, edge fragments (the intersection of two planes) are then susceptible to breakage. These removals are non-invasive, and this process sequentially rounds the sharp edges and corners of an originally angular hammerstone, reducing its mass but not significantly reducing its overall size with each fragmentation event. This fragmentation may occur recurrently, as shown by non-cortical dorsal surfaces of detached edge fragments.

The second fragmentation sequence involves the wedging initiation or 'slicing' of tabular pieces, in which portions of both the active hammer surface and its opposing surface are removed at the same time. It occurs either because of excessive force used during the hammer strike (compared to the force 
required to simply remove a protruding corner or edge), or because of the presence of internal fracture planes. This process decreases both the mass and the size of a hammer, which if continued will reduce the stone to a form where it is no longer suitable for use as a Panda hammer. Further, this reduction sequence allows for an estimate of the original hammerstone thickness, because of the preservation of opposing hammer faces. Both of the main fragmentation sequences are present in the refit sets at P100, which means that they can be reconstructed in detail from the preserved archaeological evidence, even if direct observations were unavailable.

As noted, the lack of complete hammerstones is the most striking feature of the P100 assemblage. This absence is remarkable considering that the assemblage consists of more than 400 artefacts, accumulated over a period of at least 21 years from a known Panda nut-cracking site. In some cases, usable hammers may have been completely fragmented, particularly if they were made of the more fragile granitoid and laterite materials. However, the extensive refitting efforts made in the current study, which almost doubled the number of known refits from P100, demonstrate that such a scenario is untenable for the large majority of recovered artefacts. The diorite assemblage is the most informative in this regard, as it is composed of a distinct and relatively fine-grained material that is easily recognised and allows for clear reconstruction of percussive activities - for example, the only conchoidal flake at P100 is a diorite piece. There are no diorite artefacts of sufficient size or mass to crack Panda nuts, which require hammerstones of 1-9 $\mathrm{kg}$ (Boesch and Boesch, 1983). The logical conclusion, therefore, is that any such tools have been moved offsite by the chimpanzees. Interestingly, at least part of this movement was completed by the chimpanzees in the relatively short five-year gap between the death of the Panda tree at P100 and its excavation. Furthermore, the exclusive recovery of small hammerstone fragments and the lack of complete or even substantial fragments of Panda nut hammerstones in the P100 record suggests that an exclusive focus on complete or broken hammerstones is not adequate when dealing with the behavioural prehistory of chimpanzee groups.

Chimpanzee tool transport is also recorded in the refit analysis. We have identified refitted pieces separated by 16-17 $\mathrm{m}$ at the time of excavation, representing the longest known instance of such movement in the excavated primate archaeological record. In addition, the present study found the first archaeological evidence of movement of a single hammerstone between two separate nut cracking locations. While this is unsurprising given the well-known chimpanzee transport of hammers in the Taï Forest (Boesch and Boesch, 1984a; Luncz et al., 2016), the fact that such behaviour is preserved and recoverable from the primate archaeological record is promising for studies conducted at sites where animals are either unobserved or no longer present.

Wild chimpanzee hammerstone movement has been examined under experimental conditions by Carvalho et al. (2008) in Guinea. By observing and mapping the movement of hammerstones and portable anvils provided for the animals by human experimenters, it was shown that chimpanzee oil 
palm nut cracking hammerstones may undergo a number of different movement sequences within a local area (Carvalho et al., 2008). They noted, however, that the indirect record, i.e., the final resting place of a chimpanzee hammerstone, does not provide data on its previous use location(s). They suggest that hammerstone use-life can be better understood by using direct observational data derived from primatological studies. In contrast, the results of our current study show that sufficiently fine-grained archaeological data on hammerstone fragments, including spatial and technological analysis, offer a reliable additional means for reconstructing the minimum individual movements of a hammerstone within a chimpanzee nut cracking site. This finding has the potential to allow the tracing of diachronic behavioural variation through the primate archaeological record, including, potentially detailed hammerstone use sequences at a local and regional (Luncz et al., 2016) scale. In addition, given sufficient sample size and differentiation between raw materials, it may be possible in future studies to identify a minimum number of hammerstones use at a given location.

In a wider context, since P100 was first published there have been excavations of stone tool activity areas for two more non-human primate species: Burmese long-tailed macaques (Macaca fascicularis aurea) in Thailand and bearded capuchin monkeys (Sapajus libidinosus) in Brazil (Haslam et al., 2016a, 2016b; Proffitt et al., 2016). Along with P100, these sites reveal a diversity of primate site formation processes, derived from both behavioural and environmental factors. For example, the rarity of suitable Panda hammerstones at Taï mirrors the situation for the wild capuchins at the Fazenda Boa Vista site (Visalberghi et al., 2009). In both cases, heavy but scarce hammers are required to crack tough nuts, and these hammers are not left at abandoned sites for a sufficient length of time to readily enter the archaeological record (Visalberghi et al., 2013). In contrast, wild capuchins at Serra da Capivara National Park (SCNP) (Haslam et al., 2016b) and wild macaques at Laem Son National Park (Haslam et al., 2016a) have abundant material suitable for use as hammerstones, with the result that these enter the archaeological record at a sufficient rate to enable later recovery.

Fragmentation of the Taï stone material occurs through a combination of large forces during nutcracking and the natural weakness of the rock types employed by chimpanzees. The internal structure of the hammerstone may become more susceptible to fracturing due to the development of internal fracture planes, particularly evidence in granitoid. Additionally, hammerstones most frequently fragment along the edges away from the primary use area, the centre of mass (Boesch and Boesch, 1983). This combination creates an archaeological assemblage that is essentially exclusively fragments, a collection of abundant, small, fractured pieces that currently has no direct parallel in the nut-cracking sites of other wild primates or hominins.

The discovery of stone tool flaking behaviour among the capuchins at SCNP (Proffitt et al., 2016) may provide a more suitable comparative dataset for the emergence hominin flake technology. In the latter instance, capuchins pound quartzite stones directly onto other stones to break down the tool surface, 
producing many small flakes and angular pieces in the process. Despite potential similarities in debitage density between the SCNP and chimpanzee sites, however, there is an important difference, in that the capuchins regularly create conchoidally fractured, sharp-edged flakes, whereas the Taï chimpanzees do not. This difference is likely mediated in part by the difference in percussive behaviour (stone-on-stone percussion vs nut cracking) and raw material availability and quality.

The P100 lithic material, and chimpanzee nut cracking behaviour in general, has been argued to be of importance in understanding early hominin percussive activities (McGrew, 1992; Mercader et al., 2007, 2002; Panger et al., 2003). As discussed earlier, by comparing the dimensions of fragmented pieces to known Oldowan flakes and cores, Mercader et al. (2002) linked the lithic material produced at Panda 100 with the flaking technology of early hominins. Furthermore, similar comparisons have been made between chimpanzee technology and hominin flaking elsewhere (Kortlandt, 1986; Marchant and McGrew, 2005; McGrew, 1992).

Our analysis of the P100 hammerstone reduction sequences and the technological analysis of the detached products highlights their unsuitability for direct comparison with intentional hominin knapped assemblages (de la Torre, 2010). The earliest hominin stone tool technology (Lomekwian), as well as all Oldowan lithic assemblages, indicate the intentional, repeated production of conchoidally fractured flakes (de la Torre, 2004; Delagnes and Roche, 2005; Harmand et al., 2015; Lewis and Harmand, 2016; Semaw et al., 1997). For the Oldowan, associated cores retain evidence of both simple and highly structured exploitation strategies, often adhering to flaking rules. In addition to this, ESA knappers were able to identify and rectify simple accidents and maximise the number of flakes per core through directed hammerstone impacts and advantageous use of naturally occurring angles (Delagnes and Roche, 2005; Semaw, 2000; Stout et al., 2010). The rarity at P100 of conchoidal flakes $(0.002 \%)$, coupled with the highly restricted and incidental range of fragmentation patterns prevent this assemblage from being directly comparable to even the simplest of Oldowan flaked assemblages. All detached pieces identified in this study are associated with the forceful and accidental interaction of the hammerstone with the passive anvil or the hard Panda nut target, with no instances of artefacts that resemble knapping cores.

To a large extent the degree of hammerstone fragmentation is dictated by the overall quality of the available raw material. Granitoid, for instance is highly fragmentary with numerous internal fractures, resulting in a high frequency of shatter even when used against soft organic anvils. On the other hand, diorite hammerstones are far more homogenous, with fewer internal fractures, resulting in a significantly reduced fragmented assemblage. Furthermore, the density of material in the excavated areas at P100, initially likened to the densities seen at ESA archaeological sites (Mercader et al., 2002), is largely mediated by the poor quality and highly fragmentary nature of the prevailing raw material, granitoid, whereas the density of Oldowan sites is the consequence of intentional repeated flake 
724 production. Having said this, however, the fragmentation of the Panda 100 assemblage offers an 725 opportunity to develop testable hypotheses regarding the use of organic anvils in the archaeological record. Most of the chimpanzee material can be classified as small debris and percussive technological categories, which cluster within the immediate vicinity of a used wooden anvil. It may, therefore, be hypothesised that similar technological compositions and spatial clustering within the hominin archaeological record, where there is a lack of stone anvils, may have been a consequence of organic anvil use; an otherwise archaeologically invisible behaviour.

The lack of viable hammerstones in the P100 archaeological record acts as a primate analogy for the high likelihood that both active hominin cores and hammerstones may not enter the archaeological record at the location of their use. This analogy applies directly to those stones that were still adequate for exploitation or percussive behaviour. A greater understanding of chimpanzee tool life histories will likely help generate further insights into the apparent dichotomy between the frequency of identified and expected flakes within certain hominin archaeological lithic assemblages (De la Torre and Mora, 2005; McNabb, 1998). To aid in this work, we will need additional technological and microscopic use wear characterisations to those presented in this study, in association with complementary experimental studies (Benito-Calvo et al, 2015; Arroyo, 2015; Arroyo et al., 2016; De la Torre et al., 2013). By identifying similar mechanical processes underlying percussive damage, we will be better able to identify and discriminate similar percussive behaviours in the ESA archaeological record. Ultimately, our study shows that a lack of complete stone hammerstones or anvils in the archaeological record does not necessarily preclude the presence of non-flaking percussive behaviour.

The P100 lithic assemblage represents an important dataset for investigating hominin percussive behaviour (Mora and de la Torre, 2005). Artefact categories previously associated with hominin percussive behaviour in the ESA archaeological record (Arroyo and de la Torre, 2016; De la Torre and Mora, 2005; Mora and de la Torre, 2005) are represented at P100. This finding corroborates the technological validity and cross-species viability of this classification system, and suggests that these technological classificatory groupings are valid across different raw materials, and potentially raw material qualities. In addition, this study has shown that technological categories typically associated with anvil breakage may enter the archaeological record as a consequence of hammerstone breakage, and if identified should not be inherently associated with percussive anvil breakage. The issue of

753 hammerstone breakage on organic (wooden) anvils has received little attention in the archaeological 754 literature, and may require further investigation given its presence - albeit as a minority feature - in the 755 primate tool use repertoire.

756 Our re-analysis of the first primate chimpanzee archaeological assemblages significantly updates our 757 knowledge of both the material and behaviour of which it is comprised. The importance of the P100 758 lithic collection - the 'Pandan' type assemblage (Mercader et al, 2002) - lies not only in its historical 
primacy among primate archaeological excavations, but also in the continued value of the Taï Forest material as a touchstone for comparisons with newly discovered hominin sites. Recent developments in the field of primate archaeology and human evolution suggest the need for more nuanced interpretations of chimpanzee percussive technology if we are to use it as an aid in understanding the tool use behaviour of early hominins. Cross-taxa application of analytical methods, as emphasised here, is one of the simplest and clearest ways to improve our confidence in such analogies. Finally, we note that 15 years on from the seminal P100 publication, rigorous reports of additional excavations of chimpanzee sites are very rare. Both for the purpose of understanding how chimpanzee technology evolved, and how our own technology diverged so radically from that of other primates, further exploration of the chimpanzee archaeological record is essential.

\section{Acknowledgments}

771 The study was funded by European Research Council Starting Grant \#283959 (Primate Archaeology) awarded to M.H. The study of the material was also made possible by European Research Council Starting Grant \#283366 (ORACEAF) awarded to Ignacio de la Torre. During writing, T.P was funded by a British Academy Fellowship (Project Number: 542133) and L.V.L was funded by a Leverhulme

775 Early Career Fellowship.

\section{Supplementary Online Material}

High resolution GIS maps of the Panda 100 excavations are available in the supplementary material.

All artefact measurements and technological classifications are available in supplementary material.

\section{Bibliography}

Adams, J., Delgado, S., Dubreuil, L., Hamon, C., Plisson, H., Risch, R., 2006. Functional analysis of macro-lithic artefacts, in: Functional Analysis of Macro-Lithic Artefacts. microscopic approach to the analysis of percussive artefacts from Beds I and II, Olduvai Gorge (Tanzania). J. Archaeol. Sci. 74, 23-34. 
Arroyo, A., Hirata, S., Matsuzawa, T., de la Torre, I., 2016. Nut Cracking Tools Used by Captive Chimpanzees (Pan troglodytes) and Their Comparison with Early Stone Age Percussive Artefacts from Olduvai Gorge. PLoS One 11, e0166788.

Boesch, C., Boesch, H., 1984a. Mental map in wild chimpanzees: an analysis of hammer transports for nut cracking. Primates 25, 160-170.

Boesch, C., Boesch, H., 1984b. Possible causes of sex differences in the use of natural hammers by wild chimpanzees. J. Hum. Evol. 13, 415-440.

Boesch, C., Boesch, H., 1983. Optimization of nut-cracking with natural hammers by wild chimpanzees. Behaviour 83, 265-286.

Caruana, M.V., Carvalho, S., Braun, D.R., Presnyakova, D., Haslam, M., Archer, W., Bobe, R., Harris, J.W.K., 2014. Quantifying Traces of Tool Use: A Novel Morphometric Analysis of Damage Patterns on Percussive Tools. PLoS ONE 9, e113856. doi:10.1371/journal.pone.0113856

Chavaillon, J., 1976. Evidence for the technical practices of Early Pleistocene hominids. Shungura Formations, Lower Omo Valley, Ethiopia. In. (eds) Howell, F. C et al. Earliest man and environments in the Lake Rudolf Basin. Chicago. University of Chicago Press.

Chavaillon, J., 1970. Découverte d'un niveau oldowayen dans la basse vallée de l'Omo (Ethiopie). Bull. Société Préhistorique Fr. Comptes Rendus Séances Mens. 67.

de la Torre, I., 2004. Omo revisited: evaluating the technological skills of Pliocene Hominids. Curr. Anthropol. 45, 439-465.

de la Torre, I., Benito-Calvo, A., Arroyo, A., Zupancich, A., Proffitt, T., 2013. Experimental protocols for the study of battered stone anvils from Olduvai Gorge (Tanzania). J. Archaeol. Sci. 40, 313-332.

de la Torre, I., Mora, R., 2005. Technological Strategies in the Lower Pleistocene at Olduvai Beds I \& II.

de la Torre, I., Mora, R., 2004. A technological analysis of non-flaked stone tools in Olduvai Beds I \& II. Stressing the relevance of percussion activities in the african Lower Pleistocene, in: Mourre, V., Jarry, M. (Eds.), . Presented at the La percussion directe au percuteur dur et la diversite de ses modalites d'application, PALEO 2009-2010, pp. 13-34.

de la Torre, I. 2010. Insights on the Technical Competence of the Early Oldowan. In: Nowell, A and Davidson, I, (eds.) Stone Tools and the Evolution of Human Cognition. pp. 45-65. Univ Pr of Colorado: Boulder.

Delagnes, A., Roche, H., 2005. Late Pliocene hominid knapping skills: the case of Lokalalei 2C, West Turkana, Kenya. J. Hum. Evol. 48, 435-472.

Diez-Martin, F., Sanchez, P., Dominguez-Rodrigo, M., Mabulla, A., Barba, R., 2009. Were Olduvai hominins making butchering tools or battering tools? Analysis of a recently excavated lithic 

assemblage from BK (Bed II, Olduvai Gorge, Tanzania). J. Anthropol. Archaeol. 28, 274289.

Elisabetta, V., Haslam, M., Spagnoletti, N., Fragaszy, D., 2013. Use of stone hammer tools and anvils by bearded capuchin monkeys over time and space: construction of an archeological record of tool use. J. Archaeol. Sci. 40, 3222-3232. doi:10.1016/j.jas.2013.03.021

Goren-Inbar, N., Sharon, G., Alperson-Afil, N., Herzlinger, G., 2015. A new type of anvil in the Acheulian of Gesher Benot Ya‘aqov, Israel. Phil Trans R Soc B 370, 20140353. doi:10.1098/rstb.2014.0353

Goren-Inbar, N., Sharon, G., Melamed, Y., Kislev, M.E., 2002. Nuts, nut cracking, and pitted stones at Gesher Benot Ya'aqov, Israel. Proc. Natl. Acad. Sci. U. S. A. 99, 2455-2460.

Harmand, S., Lewis, J.E., Feibel, C.S., Lepre, C.J., Prat, S., Lenoble, A., Boës, X., Quinn, R.L., Brenet, M., Arroyo, A., Taylor, N., Clément, S., Daver, G., Brugal, J.-P., Leakey, L., Mortlock, R.A., Wright, J.D., Lokorodi, S., Kirwa, C., Kent, D.V., Roche, H., 2015. 3.3million-year-old stone tools from Lomekwi 3, West Turkana, Kenya. Nature 521, 310-315. doi:10.1038/nature14464

Haslam, M., Hernandez-Aguilar, R.A., Proffitt, T., Arroyo, A., Falótico, T., Fragaszy, D., Gumert, M., Harris, J.W., Huffman, M.A., Kalan, A.K., 2017. Primate archaeology evolves. Nature Ecology \& Evolution 1, 1431.

Haslam, M., 2012. Towards a prehistory of primates. Antiquity 86, 299-315.

Haslam, M., Hernandez-Aguilar, A., Ling, V., Carvalho, S., de la Torre, I., DeStefano, A., Du, A., Hardy, B., Harris, J., Marchant, L., Matsuzawa, T., McGrew, W.C., Mercader, J., Mora, R., Petraglia, M., Roche, H., Visalberghi, E., Warren, R., 2009. Primate archaeology. Nature 460, 339-344.

Haslam, M., Luncz, L., Pascual-Garrido, A., Falótico, T., Malaivijitnond, S., Gumert, M., 2016a. Archaeological excavation of wild macaque stone tools. J. Hum. Evol. doi:10.1016/j.jhevol.2016.05.002

Haslam, M., Luncz, L.V., Staff, R.A., Bradshaw, F., Ottoni, E.B., Falótico, T., 2016b. Pre-Columbian monkey tools. Curr. Biol. 26, R521-R522.

Isaac, G.L., 1976. Plio-Pleistocene artifact assemblages from east Rudolf, Kenya, in: Early Man and Environments in the Lake Rudolf Basin: Stratigraphy, Paleoecology and Evolution. University of Chicago Press, Chicago, pp. 552-564.

Kortlandt, A., 1986. The use of stone tools by wild-living chimpanzees and earliest hominids. J. Hum. Evol. 15, 77-132.

Leakey, M.D., 1971. Olduvai Gorge, Vol. 3. Excavations in Beds I and II, 1960-1963. Cambridge University Press, Cambridbe. 
Lewis, J.E., Harmand, S., 2016. An earlier origin for stone tool making: implications for cognitive evolution and the transition to Homo. Phil Trans R Soc B 371, 20150233. doi:10.1098/rstb.2015.0233

Luncz, L.V., Proffitt, T., Kulik, L., Haslam, M., Wittig, R.M., 2016. Distance-decay effect in stone tool transport by wild chimpanzees. Proc. R. Soc. B Biol. Sci.

Marchant, L.F., McGrew, W.C., 2005. Percussive technology: Chimpanzee baobab smashing and the evolutionary modelling of hominin knapping, in: Roux, V., Brill, B. (Eds.), Stone Knapping, the Necessary Conditions for a Uniquely Hominin Behaviour. McDonald Institute for Archaeological Research, Cambridge, pp. 341-350.

McGrew, W.C., 1992. Chimpanzee material culture: implications for human evolution. Cambridge University Press, Cambridge.

McNabb, J., 1998. On the move. Time, averaging and resource transport in the Oldowan.

Mercader, J., Barton, H., Gillespie, J., Harris, J., Kuhn, S., Tyler, R., Boesch, C., 2007. 4,300-year-old chimpanzee sites and the origins of percussive stone technology. Proc. Natl. Acad. Sci. U. S. A. $104,3043-3048$.

Mercader, J., Panger, M.A., Boesch, C., 2002. Excavation of a chimpanzee stone tool site in the african rainforest. Science 296, 1452-1455.

Merrick, H.V., De Heinzelin, J., Haesaerts, P., Howell, F.C., 1973. Archaeological Occurrences of Early Pleistocene Age from the Shungura Formation, Lower Omo Valley, Ethiopia. Nature 242, 572-575. doi:10.1038/242572a0

Merrick, H.V., Merrick, J.P., 1976. Archaeological occurences of Earlier Pleistocene Age from the Shungura Formation, in: Coppens, Y., Howe, F.C., Isaac, G.L., Leakey, R.E. (Eds.), Earliest Man and Environment in the Lake Rudolf Basin. University of Chicago Press, Chicago, pp. $574-584$.

Mora, R., de la Torre, I., 2005. Percussion tools in Olduvai Beds I and II (Tanzania): Implications for early human activities. J. Anthropol. Archaeol. 24, 179-192.

Panger, M.A., Brooks, A.S., Richmond, B.G., Wood, B., 2003. Older than the Oldowan? Rethinking the emergence of hominin tool use. Evol. Anthropol. Issues News Rev. 11, 235-245. doi:10.1002/evan.10094

Pelegrin, J., 2005. Remarks about archaeological techniques and methods of knapping: Elements of a cognitive approach to stone knapping., in: Roux, V., Bril, B. (Eds.), Stone Knapping: The Necessary Conditions for a Uniquely Hominid Behaviour. McDonald Institute Monograph Series, Cambridge. McDonald Institute monograph series, Cambridge, pp. 23-33.

Proffitt, T., Luncz, L.V., Falótico, T., Ottoni, E.B., de la Torre, I., Haslam, M., 2016. Wild monkeys flake stone tools. Nature.

Schick, K., Toth, N., 2006. An overview of the Oldowan Industrial Complex: the sites and the nature of their evidence. Oldowan Case Stud. Earliest Stone Age 3-42. 
Semaw, S., 2000. The World's Oldest Stone Artefacts from Gona, Ethiopia: Their Implications for Understanding Stone Technology and Patterns of Human Evolution Between 2.6 - 1.5 Million Years Ago. J. Archaeol. Sceince 27, 1197-1214.

Semaw, S., Renne, P., Harris, J.W., Feibel, C.S., Bernor, R.L., Fesseha, N., Mowbray, K., 1997. 2.5million-year-old stone tools from Gona, Ethiopia. Nature 385, 333-336.

Stout, D., Semaw, S., Rogers, M.J., Cauche, D., 2010. Technological variation in the earliest Oldowan from Gona, Afar, Ethiopia. J. Hum. Evol. 58, 474-491.

Turq, A., 1992. Le Paleolithique inferieur et moyen les vallees de la Dordogne et due Lot. Universite de Bordeaux I.

Visalberghi, E., Spagnoletti, N., Ramos da Silva, E.D., Andrade, F.R.D., Ottoni, E., Izar, P., Fragaszy, D., 2009. Distribution of potential suitable hammers and transport of hammer tools and nuts by wild capuchin monkeys. Primates 50, 95-104. doi:10.1007/s10329-008-0127-9

\section{List of Tables}

Table 1: Calibrated radiocarbon ages from the Panda 100 site (Mercader et al., 2007), calibrated using

OxCal 4.2 and the IntCal13 curve

Table 2: Absolute and relative frequency of technological artefact types for each raw material at

Panda 100

Table 3: Dimensional data for each percussive technological category at Panda 100

Table 4: All refits identified in the current study of the Panda 100 lithic assemblage. * No direct measurement possible for entire refit sequence, distance was estimated based on grid reference. ${ }^{1}$ No direct measurement possible for a single piece in refit set, distance was estimated based on grid reference.

Table 5: Percussive damage identified on lithic artefacts from P100

\section{List of Figures}

Figure 1: (A) Location map of Panda 100 (P100) site. (B) Excavation and refit map of P100 lithic assemblage (adapted from (Mercader et al., 2002) 
Figure 2: Examples of detached percussive products from lithic hammerstones at P100. A) Granitoid and diorite edge pieces (Group 1.1). B) Granitoid and diorite corner fragments (Group 1.2). C) Examples of granitoid and laterite small debris $(<20 \mathrm{~mm})($ Group 5$)($ Scale $=5 \mathrm{~cm})$.

Figure 3: Examples of detached percussive artefacts from lithic hammerstones at P100. A) Detached diorite conchoidal flake (Group 2.3). B) Detached diorite typical hammerstone flakes (Group 3). $($ Scale $=5 \mathrm{~cm})$

Figure 4: Refit Sets 1 and 2 from Panda 100. A) Refit Set 1: Two laterite angular chunks. B) Refit Set 2: Distally fractured, detached corner fragment of a diorite hammerstone $($ Scale $=5 \mathrm{~cm})$

Figure 5: Refit Sets 3 and 4 from Panda 100. A) Refit set 3: Four granitoid fragments, two edge fragments and two corner fragments. B) Refit Set 4: Two granitoid fragments representing a corner region of a hammerstone $($ Scale $=5 \mathrm{~cm})$

Figure 6: Refit Set 5, 6 and 7 from Panda 100. A) Refit Set 5: Two angular chunks representing the edge of a granitoid hammerstone. B) Refit Set 6: Two corner fragments and one angular chunk representing a corner detachment of a granitoid hammer. C) Refit Set 7: Corner refit of a tabular granitoid hammerstone consisting of three corner fragments and one edge fragment. (Scale $=5 \mathrm{~cm}$ )

Figure 7: Refit Sets 8 and 9 from Panda 100. A) Refit Set 8: Edge fragment of a granitoid hammerstone consisting of one corner fragment and one edge fragment. B) Refit Set 9: Minor fragmentation of a laterite cobble. $($ Scale $=5 \mathrm{~cm})$

Figure 8: Refit Sets 10, 11, and 12 from Panda 100. A) Refit Set 10: Five granitoid fragments (three corner fragments, two angular chunks) representing an extensive fragmentation of a large hammerstone. B) Refit Set 12: Five granitoid fragments (two edge fragments, three angular chunks / fragments) of a larger hammerstone corner region. C) Refit Set 11: Edge fragment of a granitoid hammerstone consisting of one angular chunk and one edge fragment. (Scale $=5 \mathrm{~cm}$ )

Figure 9: Spatial map of Panda 100 excavations highlighting all refit sets identified in this study

Figure 10: All mapped artefacts separated by spit with corresponding refit sets for each anvil location

Figure 11: Microscopic damage of percussive artefacts at Panda 100. A) Granitoid corner fragment (Group 1.2) with clear percussive damage. 1 and 2. Cortical, undamaged areas, showing intact quartz crystals and flat smooth surface (scale $=500 \mu \mathrm{m}$ and $1000 \mu \mathrm{m}$ ). 3 and 4 . Impact point showing 
significant crushing and development of small steps along with detachment of quartz crystals (scale $=$ $971500 \mu \mathrm{m}$ and $1000 \mu \mathrm{m}$ ). B) Granitoid edge fragment (Group 1.1). 1. Undamaged cortical surface (scale $972=500 \mu \mathrm{m}) .2,3$ and 4 . $\mathrm{V}$-shaped impact points along the edge and interior of the percussive surface 973 (scale $3000 \mu \mathrm{m}, 3000 \mu \mathrm{m}$ and $500 \mu \mathrm{m}$ ).

975 Figure 12: Microscopic damage of percussive artefacts at Panda 100. A) Granitoid corner fragment 976 with clear percussive damage. 1. Cortical, undamaged surface $($ scale $=500 \mu \mathrm{m})$. 2. V-shaped impact 977 point (scale $3000 \mu \mathrm{m})$. 3. Crushing and step fractures associated with impact point (scale $=3000 \mu \mathrm{m})$.

978 4. Impact point showing significant crushing of quartz crystals and matrix (scale $=1000 \mu \mathrm{m})$. B)

979 Diorite corner fragment with possible pitted surface. 1 and 2. Cortical, undamaged surfaces preserving 980 intact crystals and matrix. 3 and 4. Undamaged surface from within the pitted surface, showing intact 981 crystals and matrix $($ scale $=2000 \mu \mathrm{m})$.

983 Figure 13: Density map of all artefacts at Panda 100 at each anvil location 984 


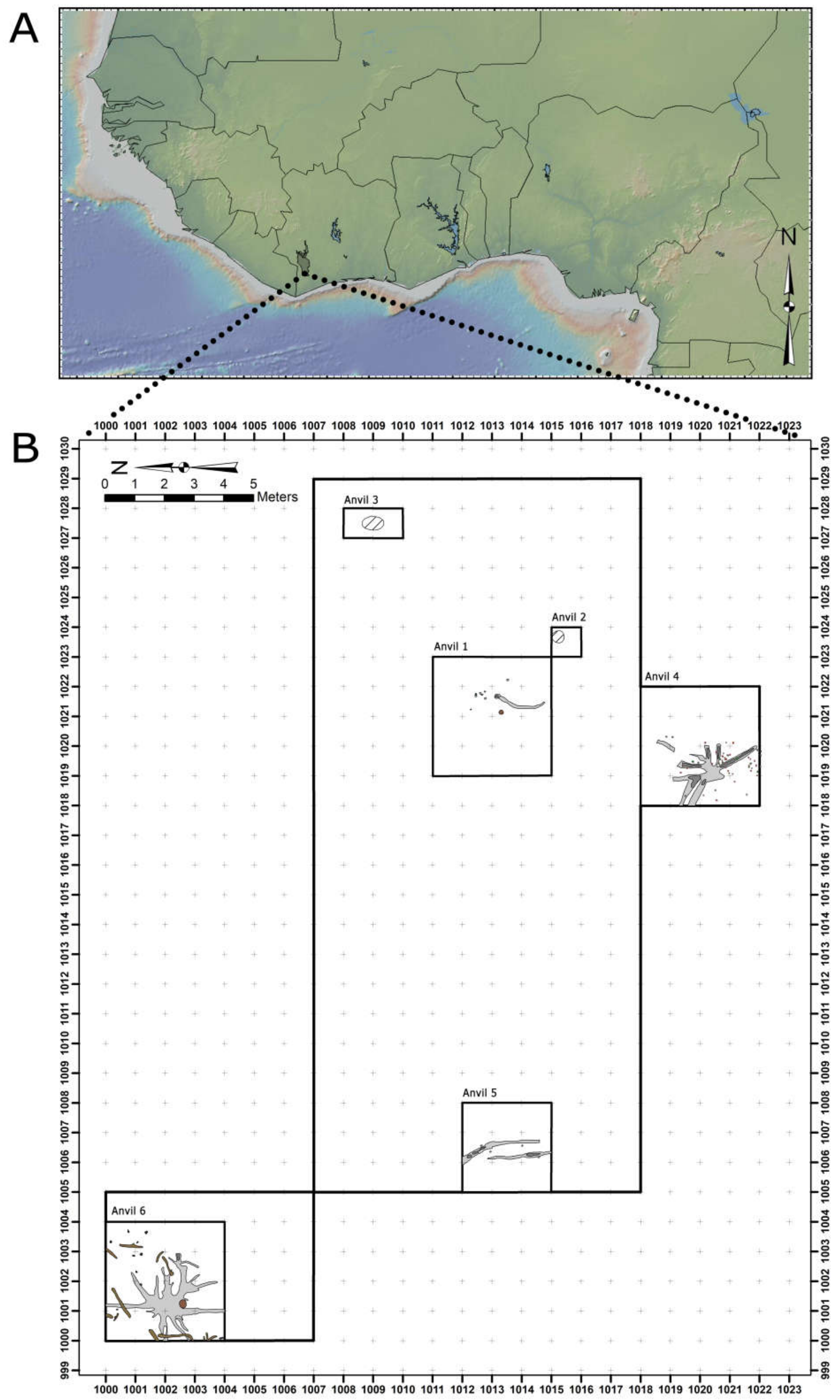




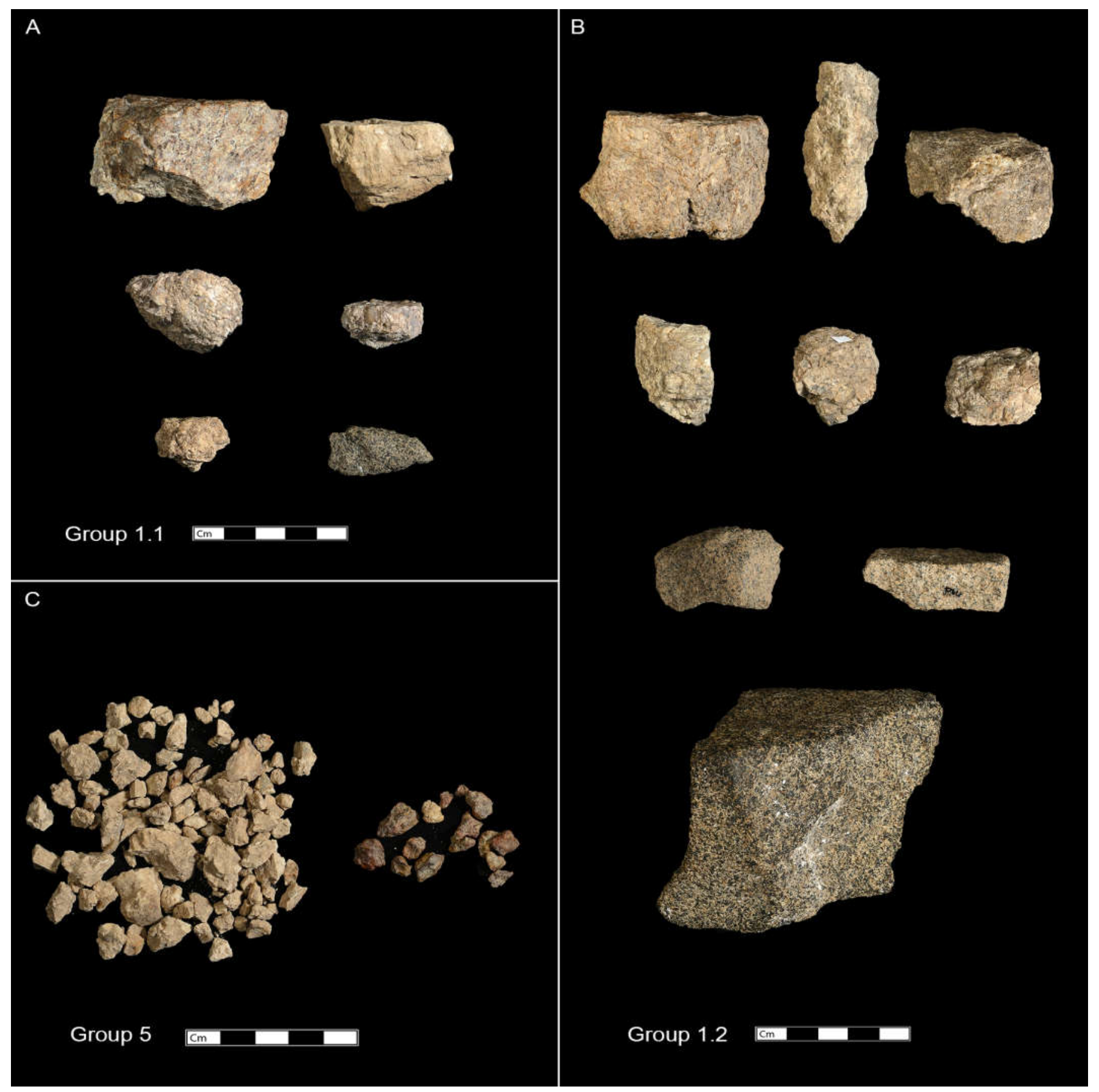




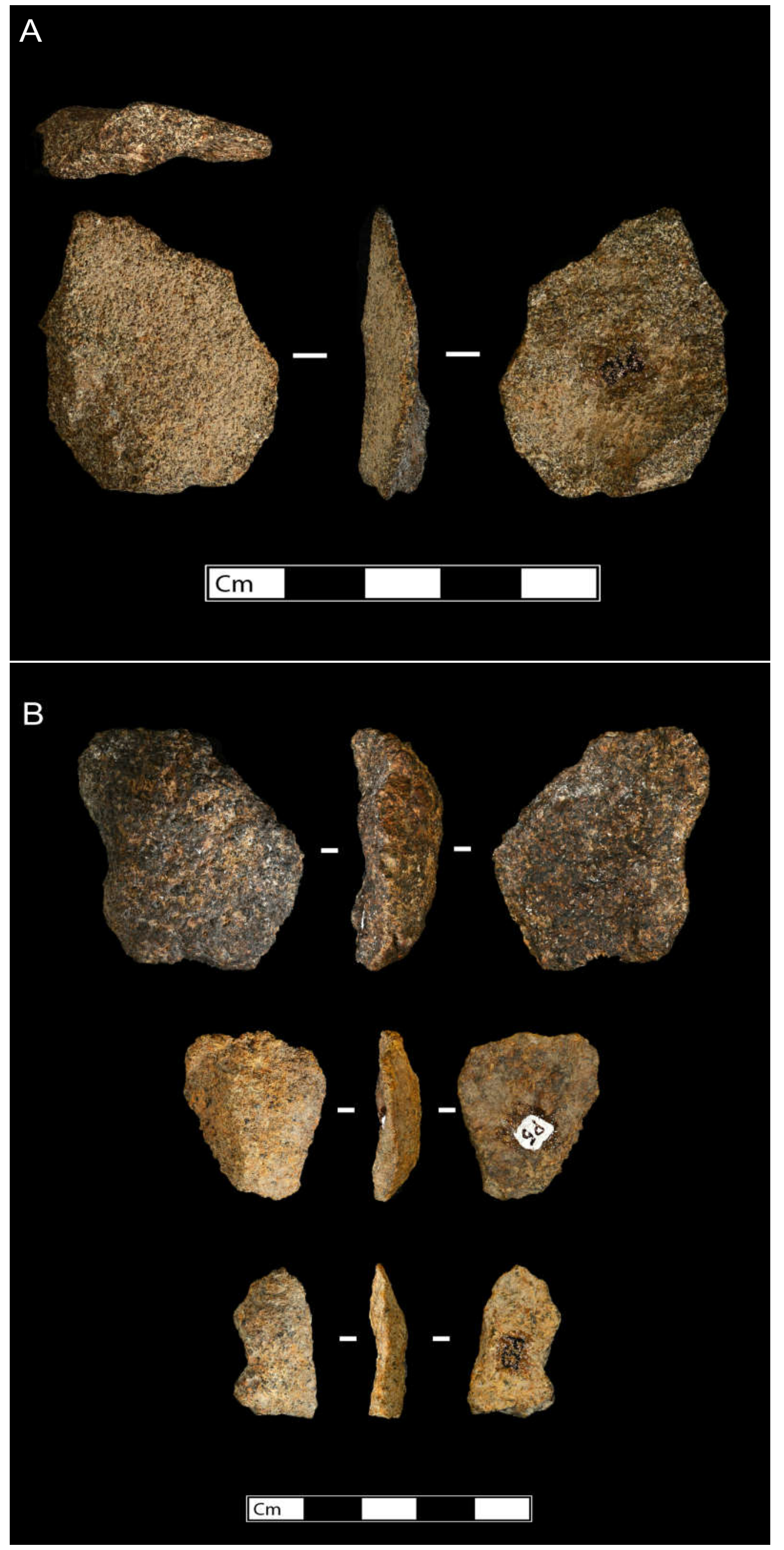




\section{A}
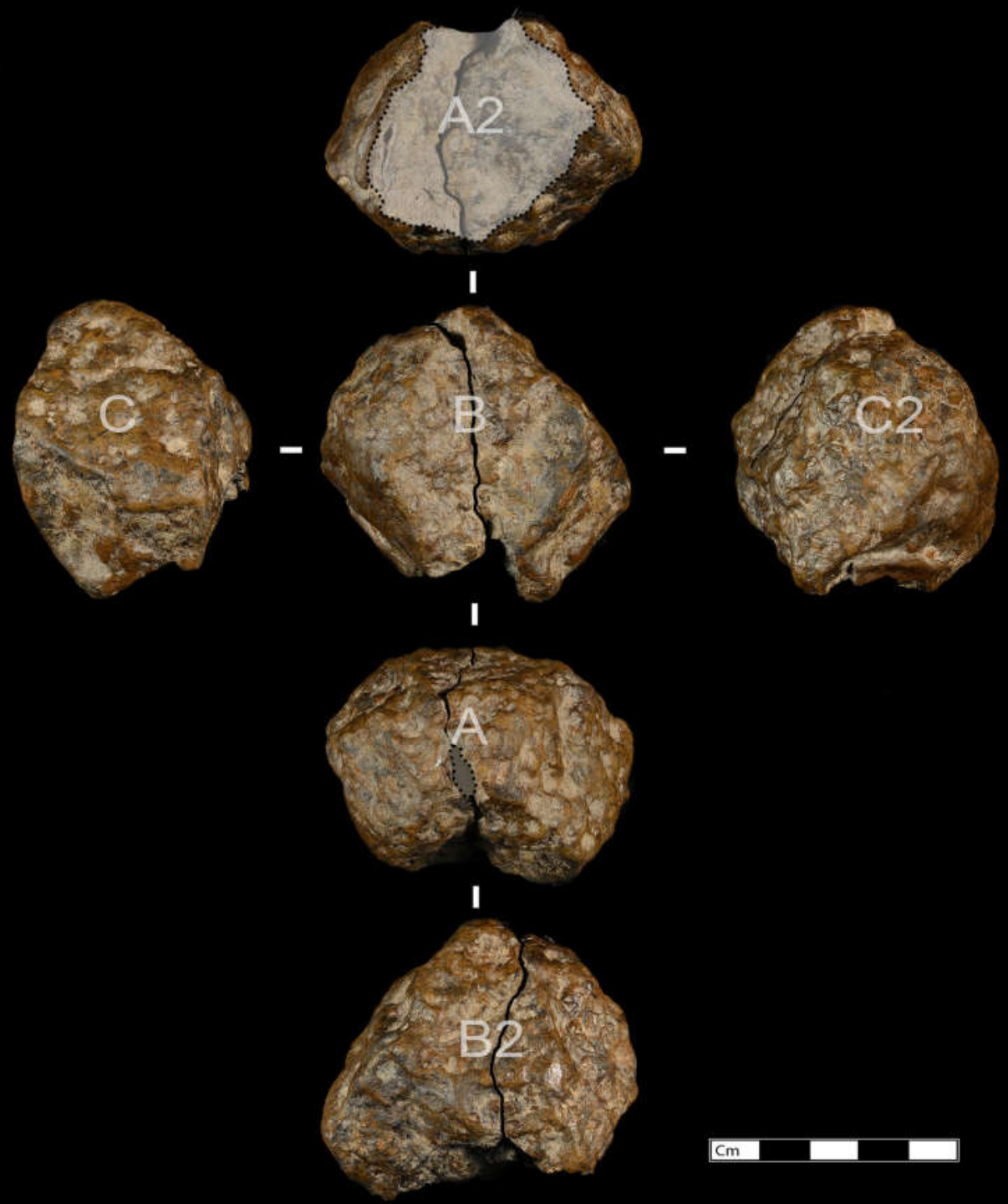

\begin{tabular}{llll}
\hline $\mathrm{Cm}$ & $\square$
\end{tabular}

\section{B}
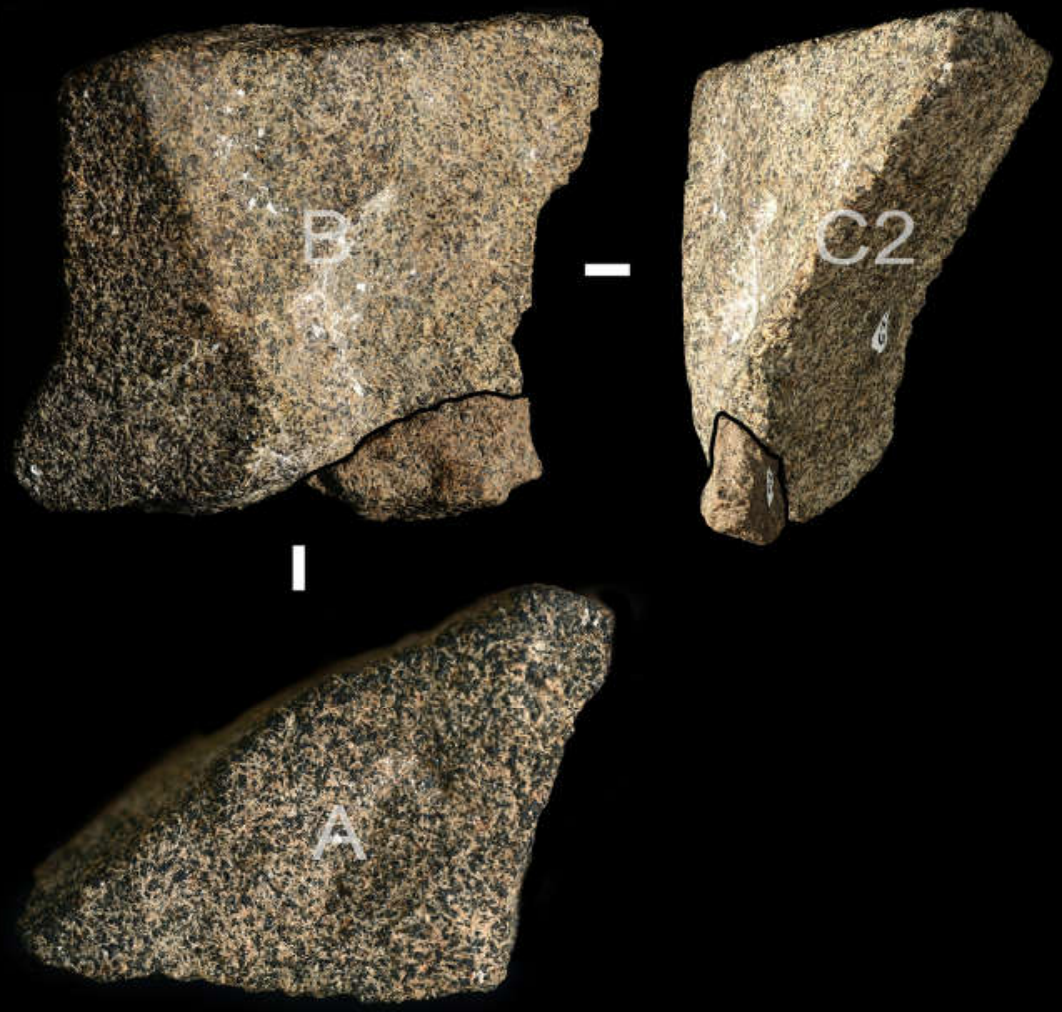

$\mathrm{Cm}$ 

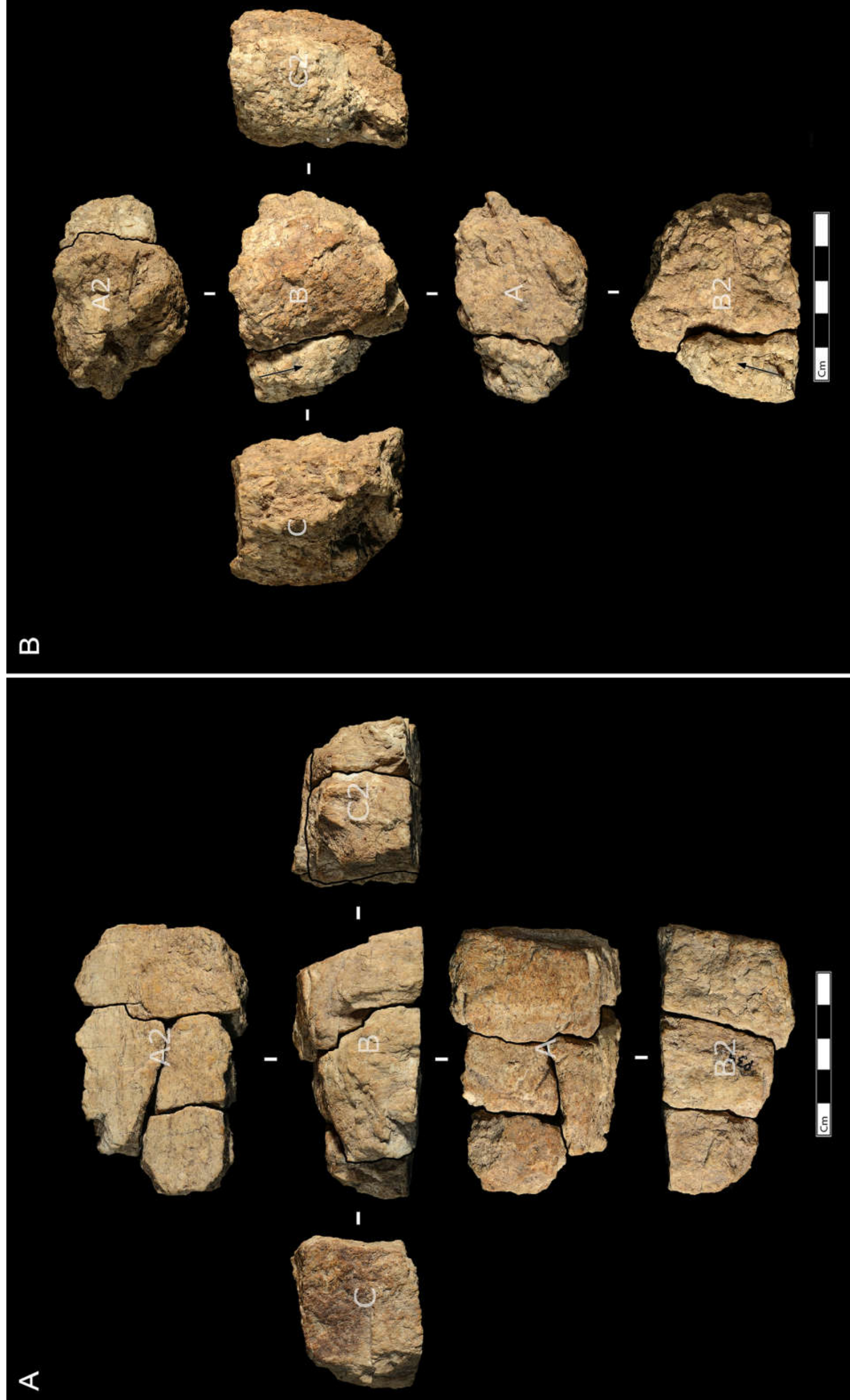


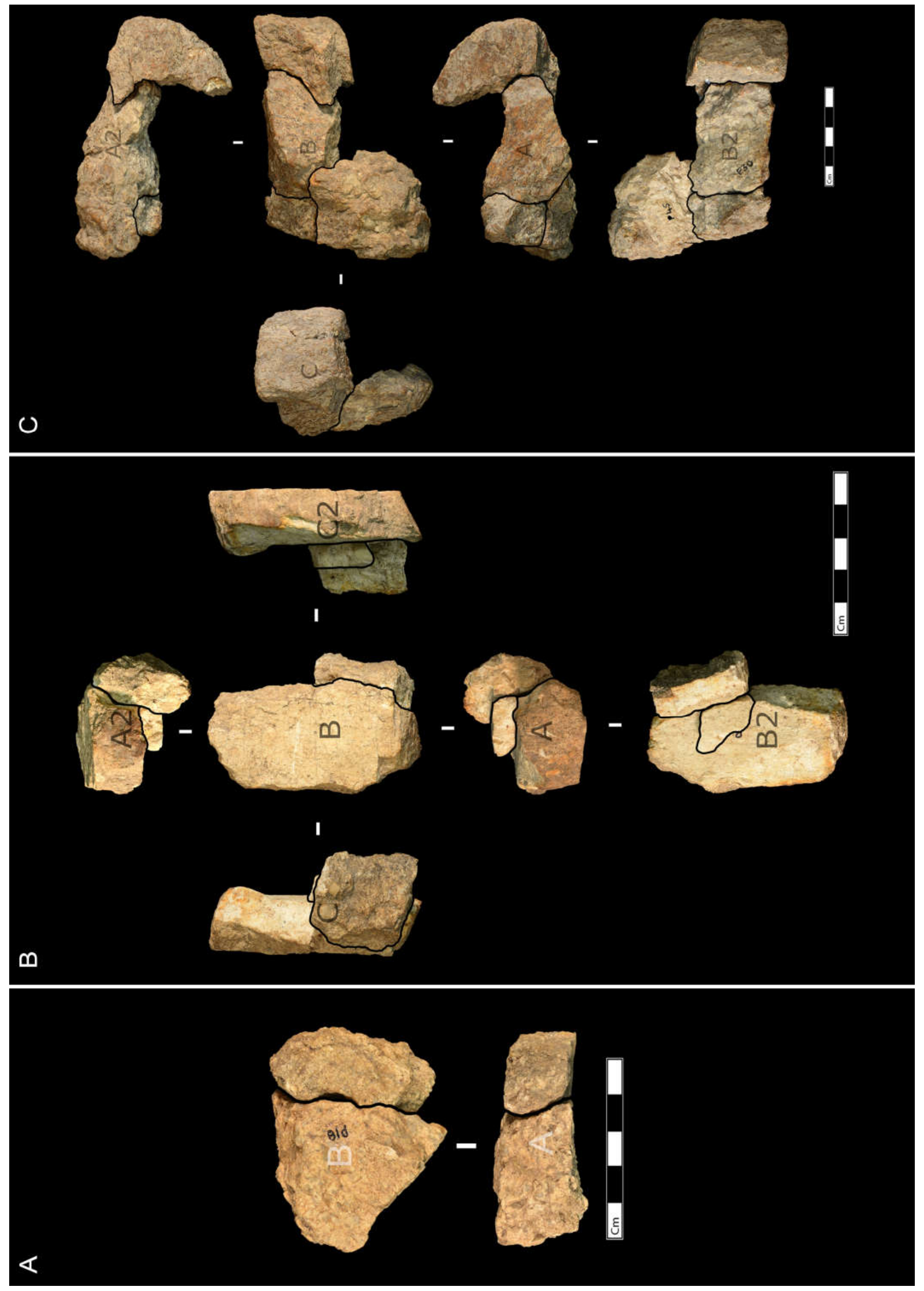



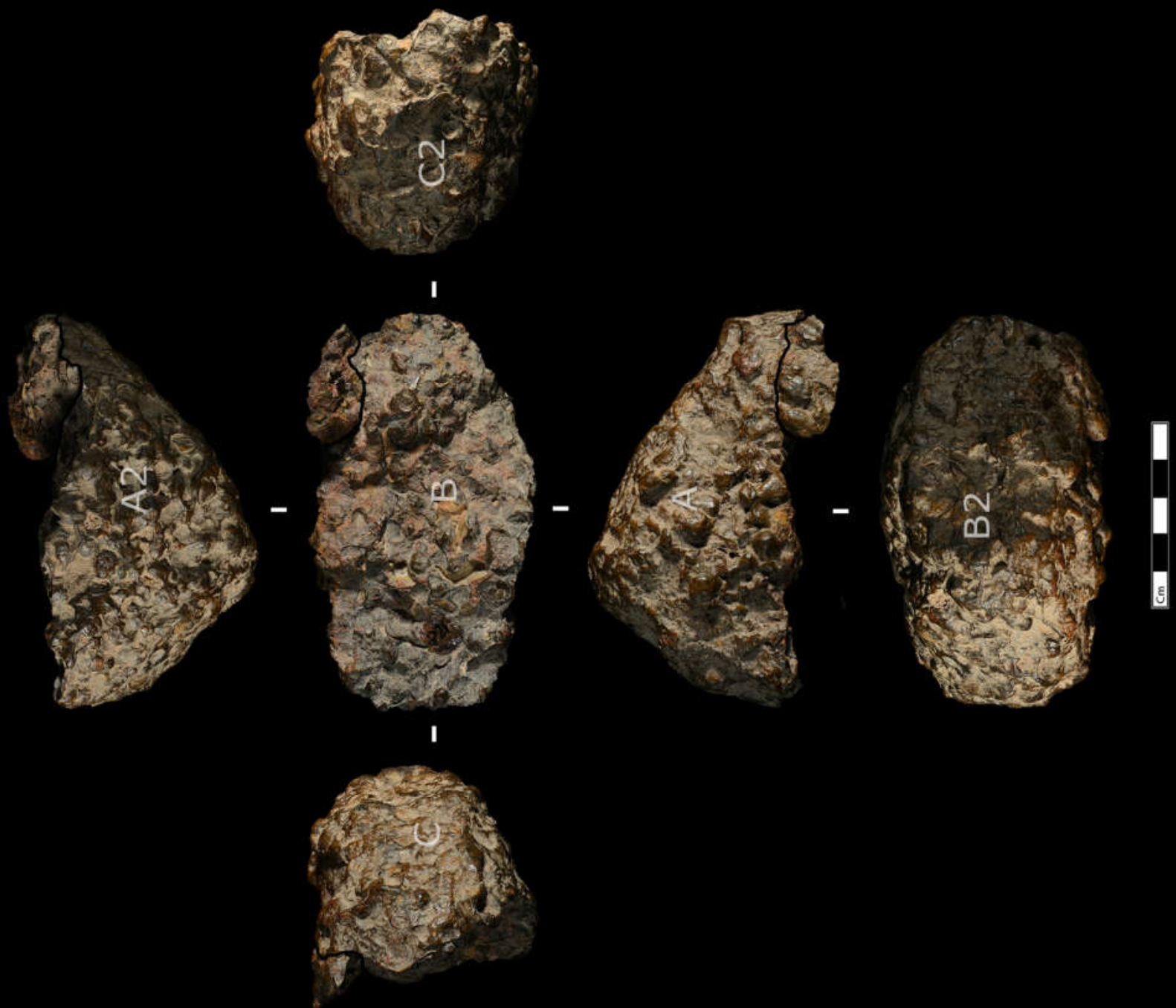

$m$
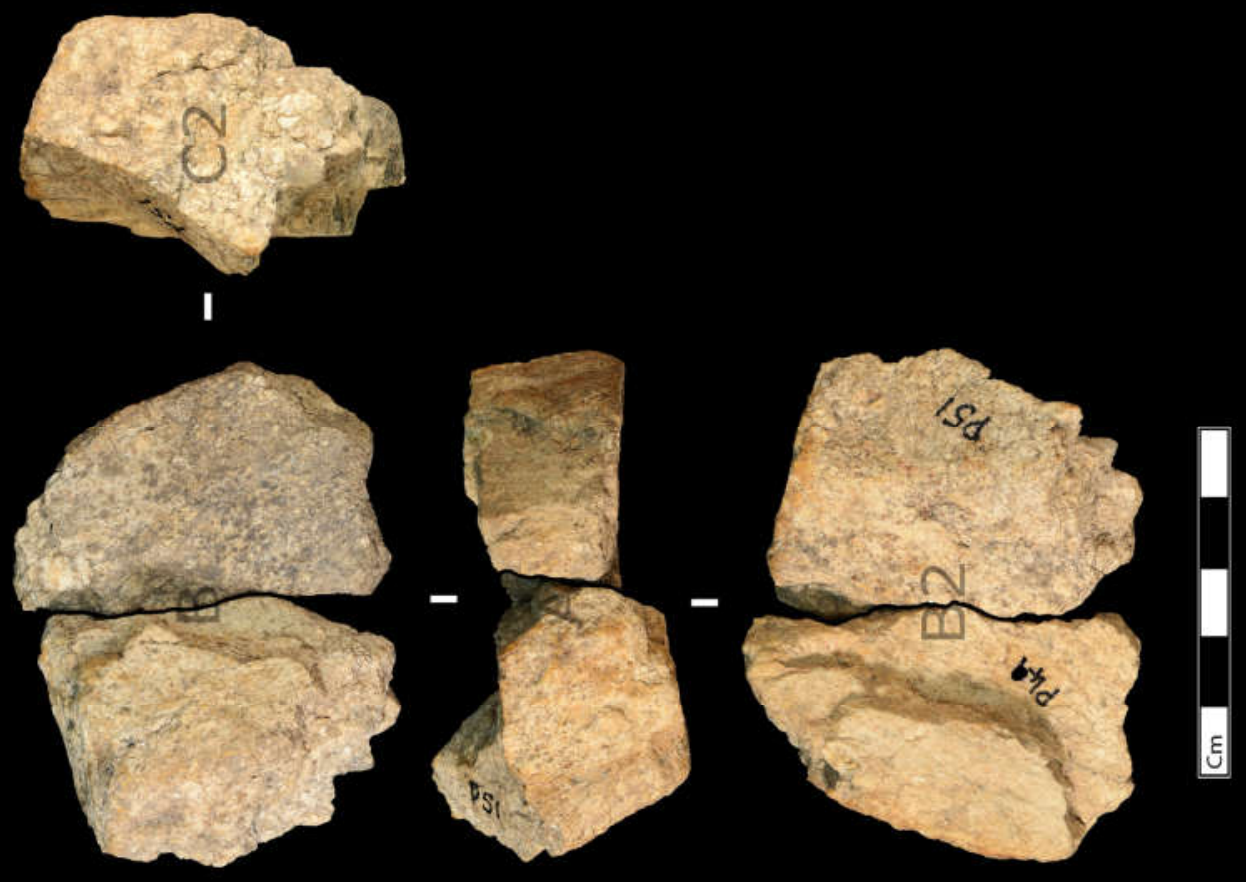

$\varangle$ 


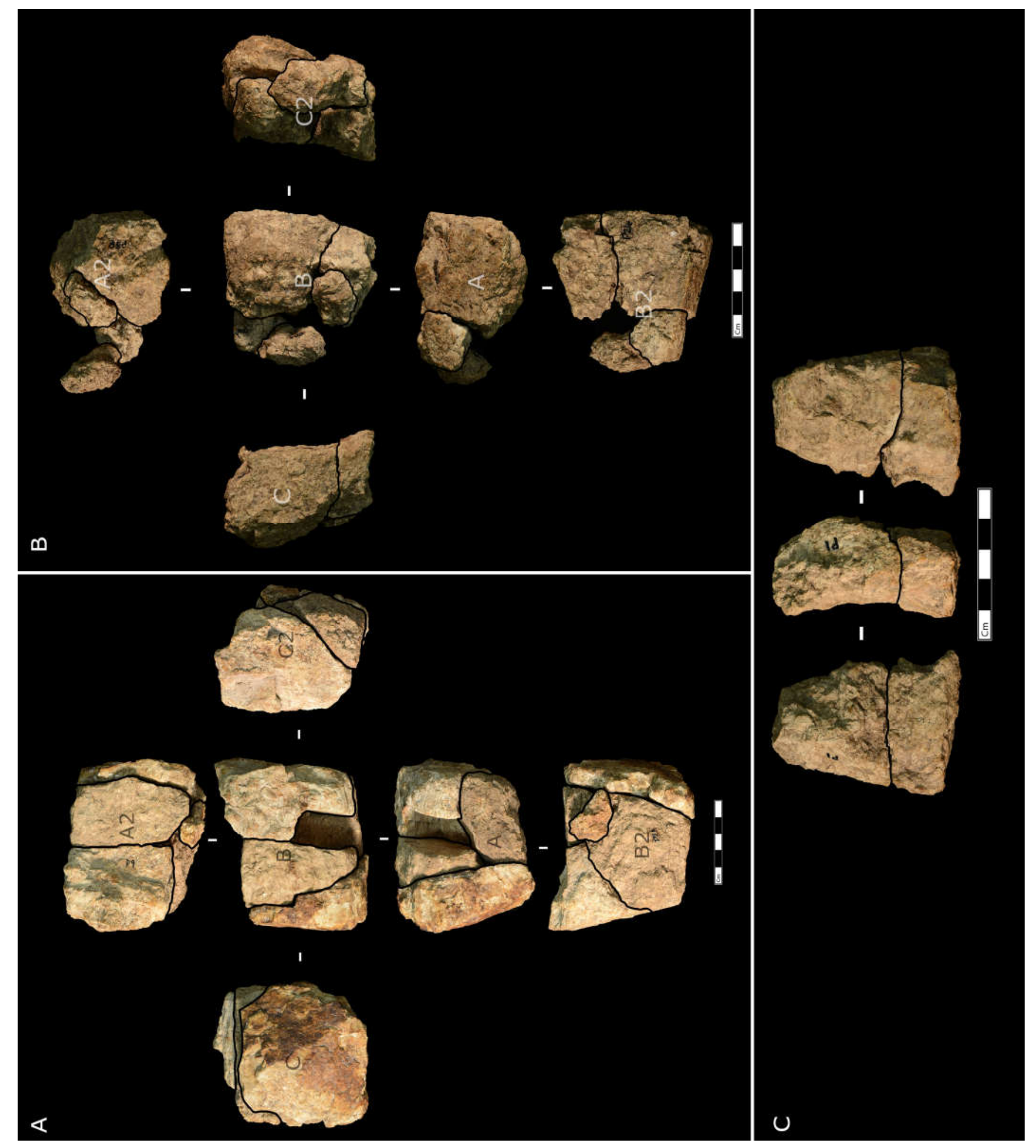




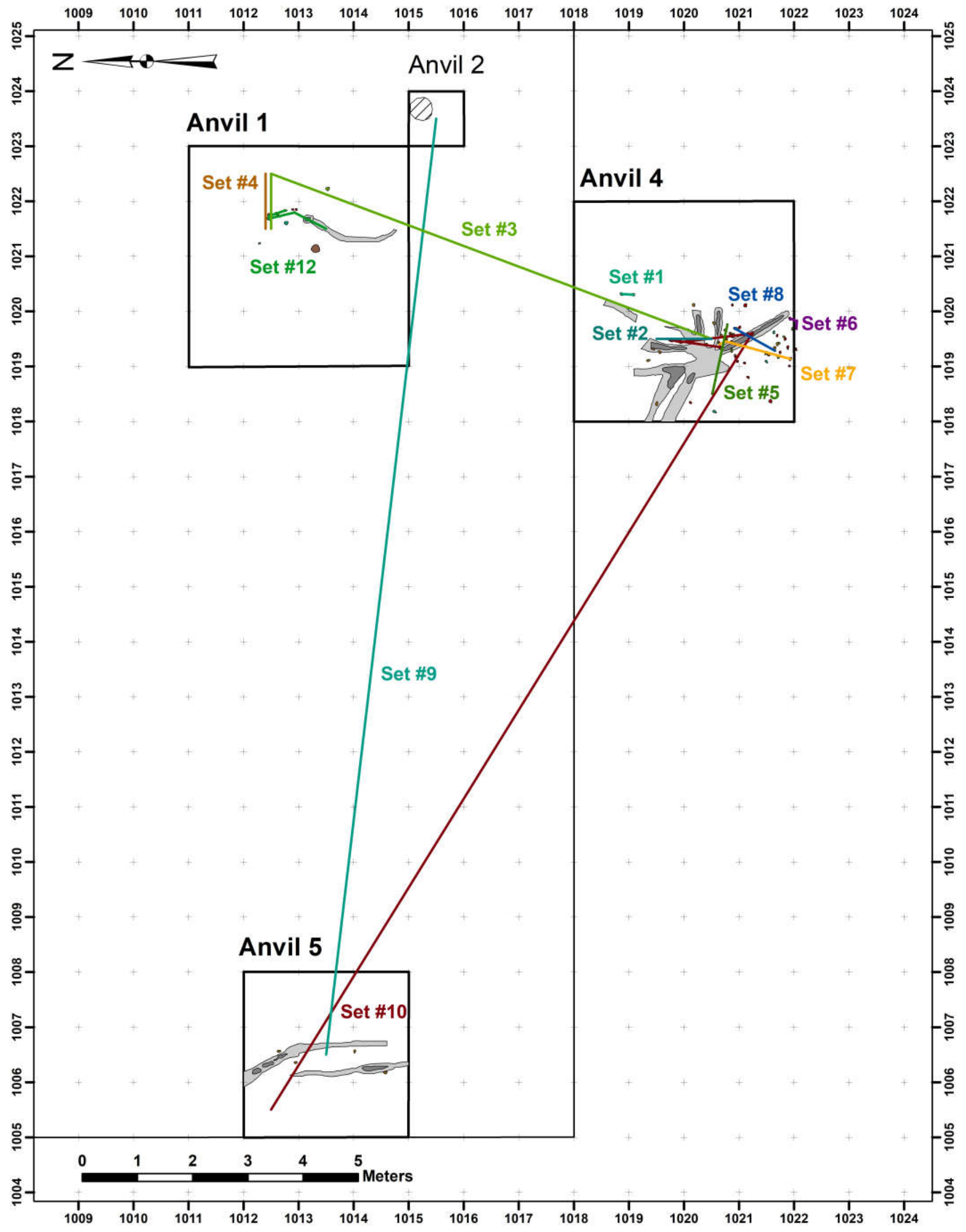



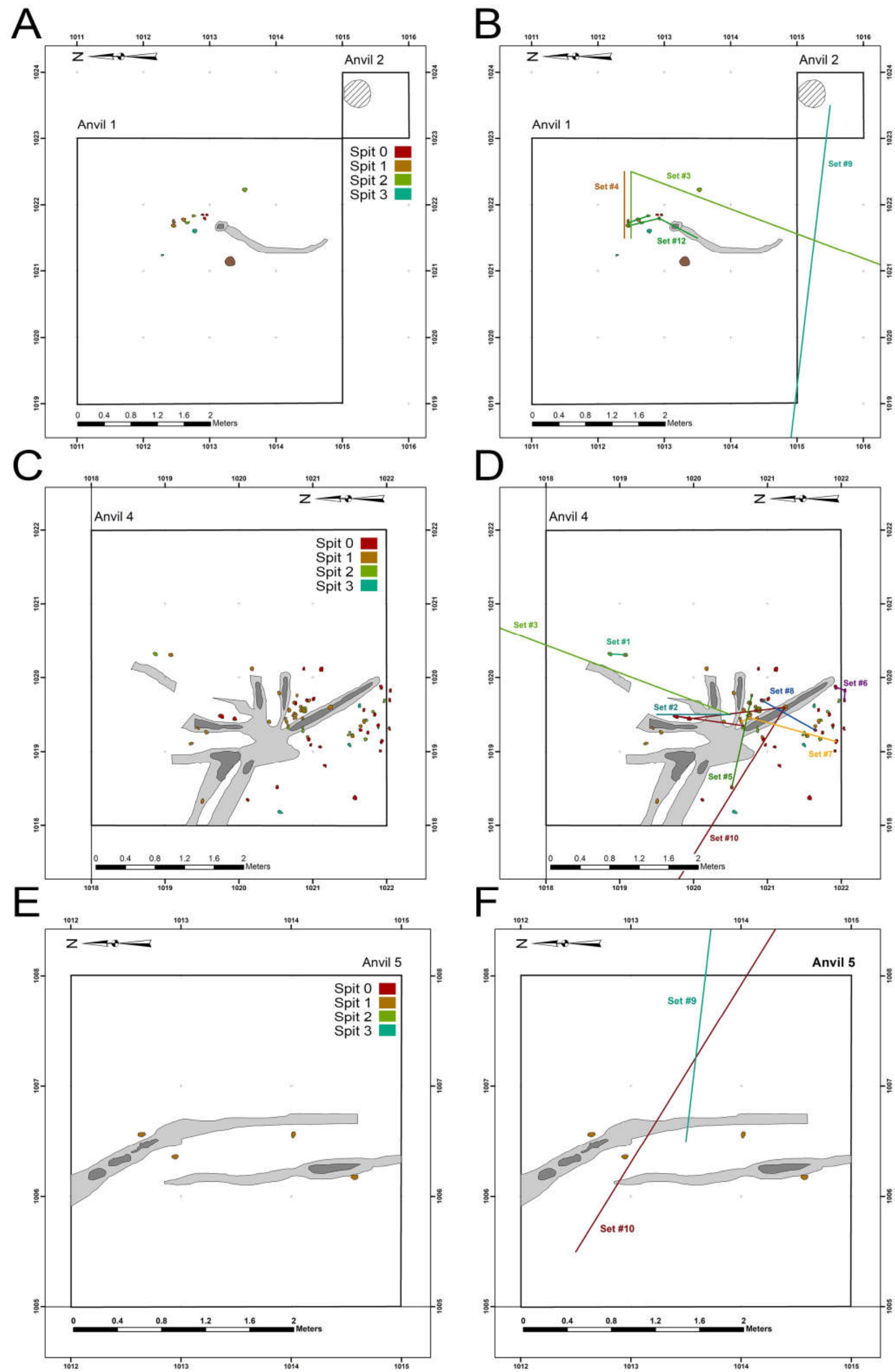

$\mathrm{F}$

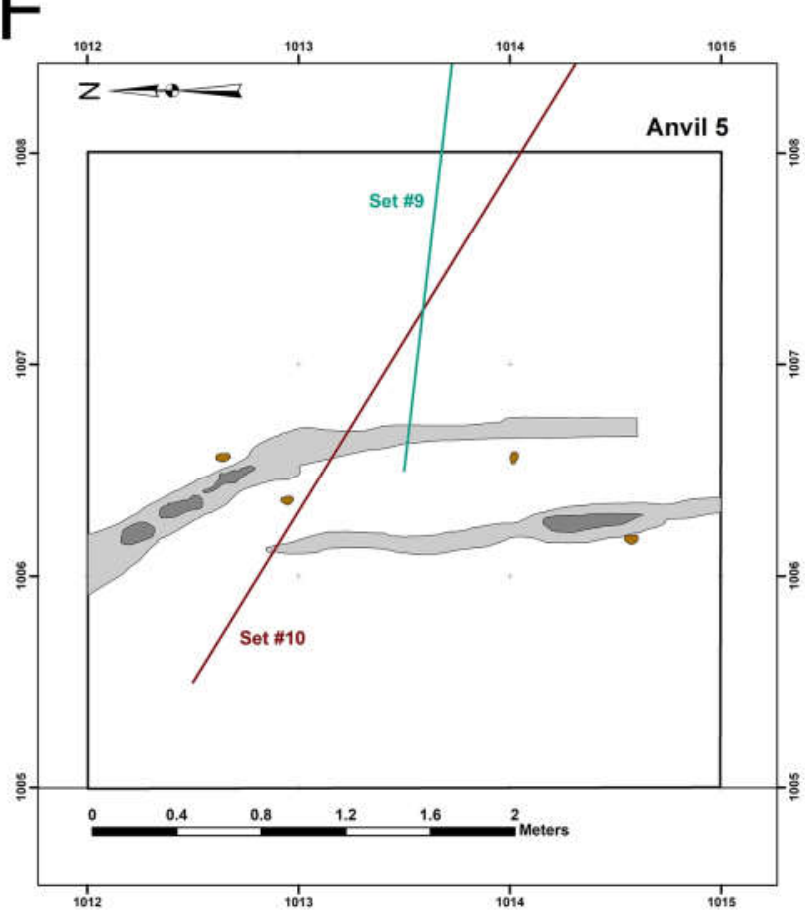


A
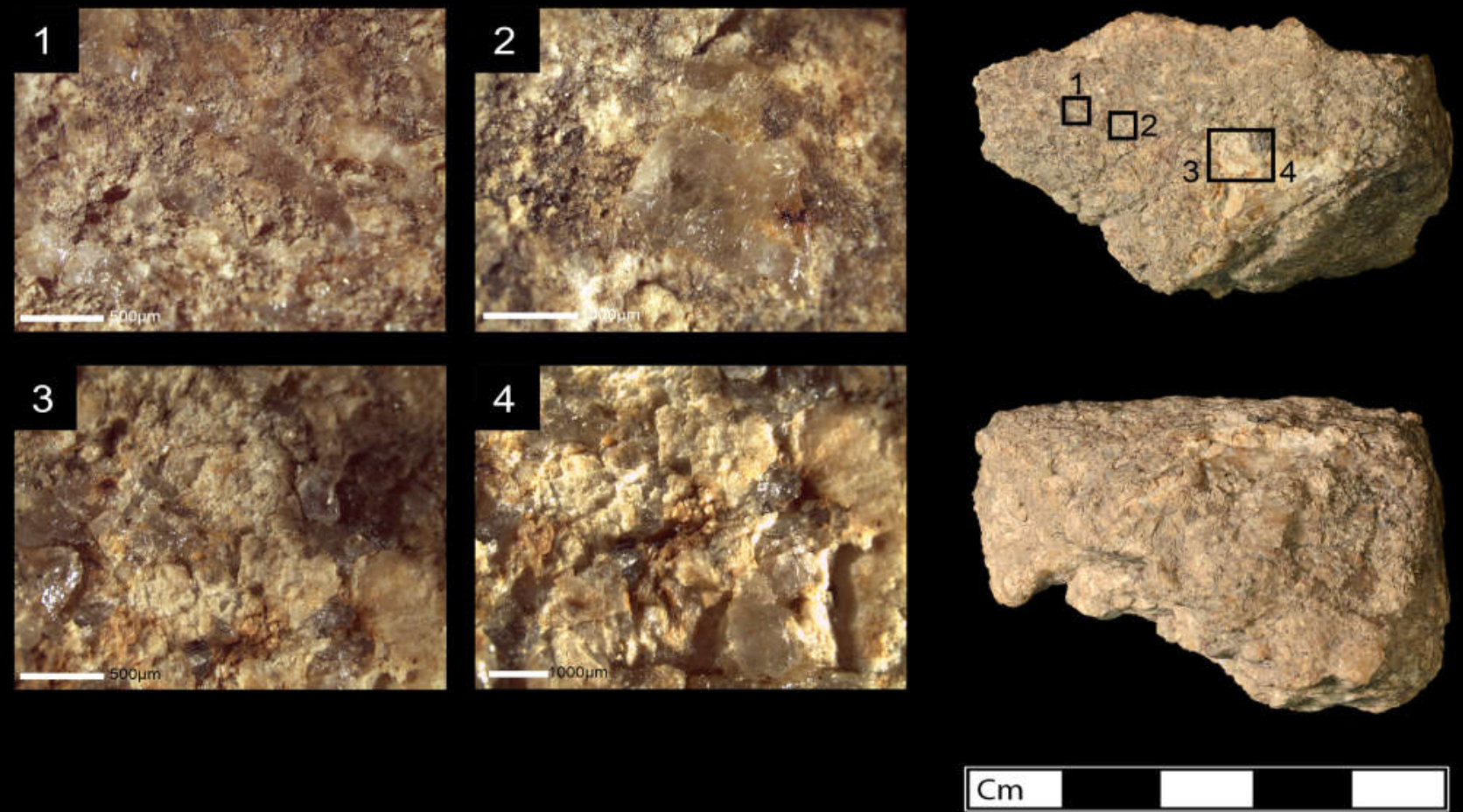

B
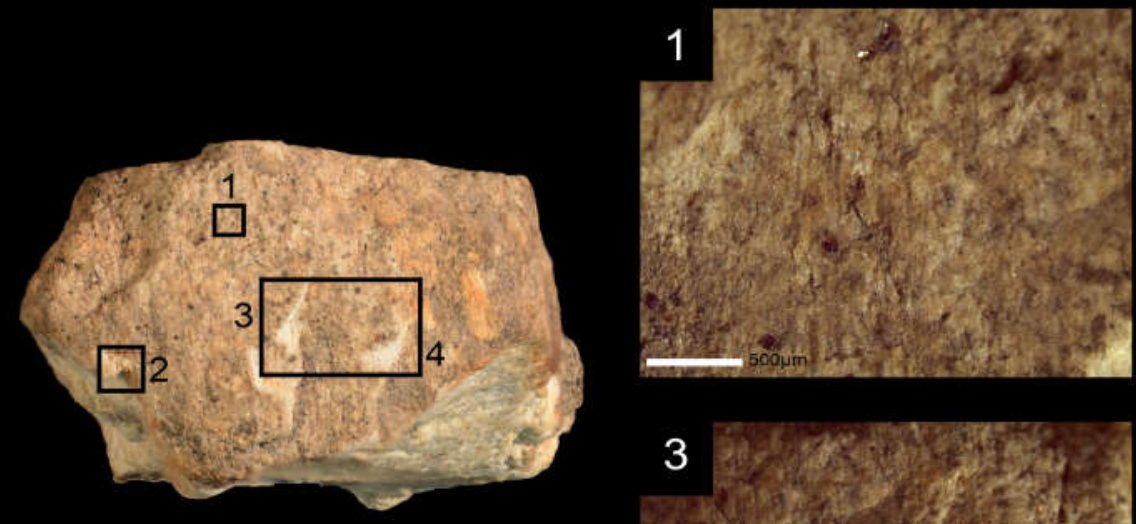

2
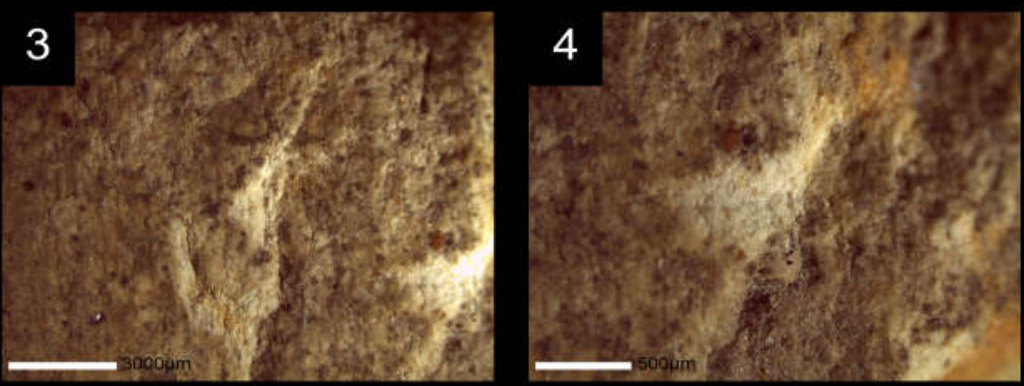

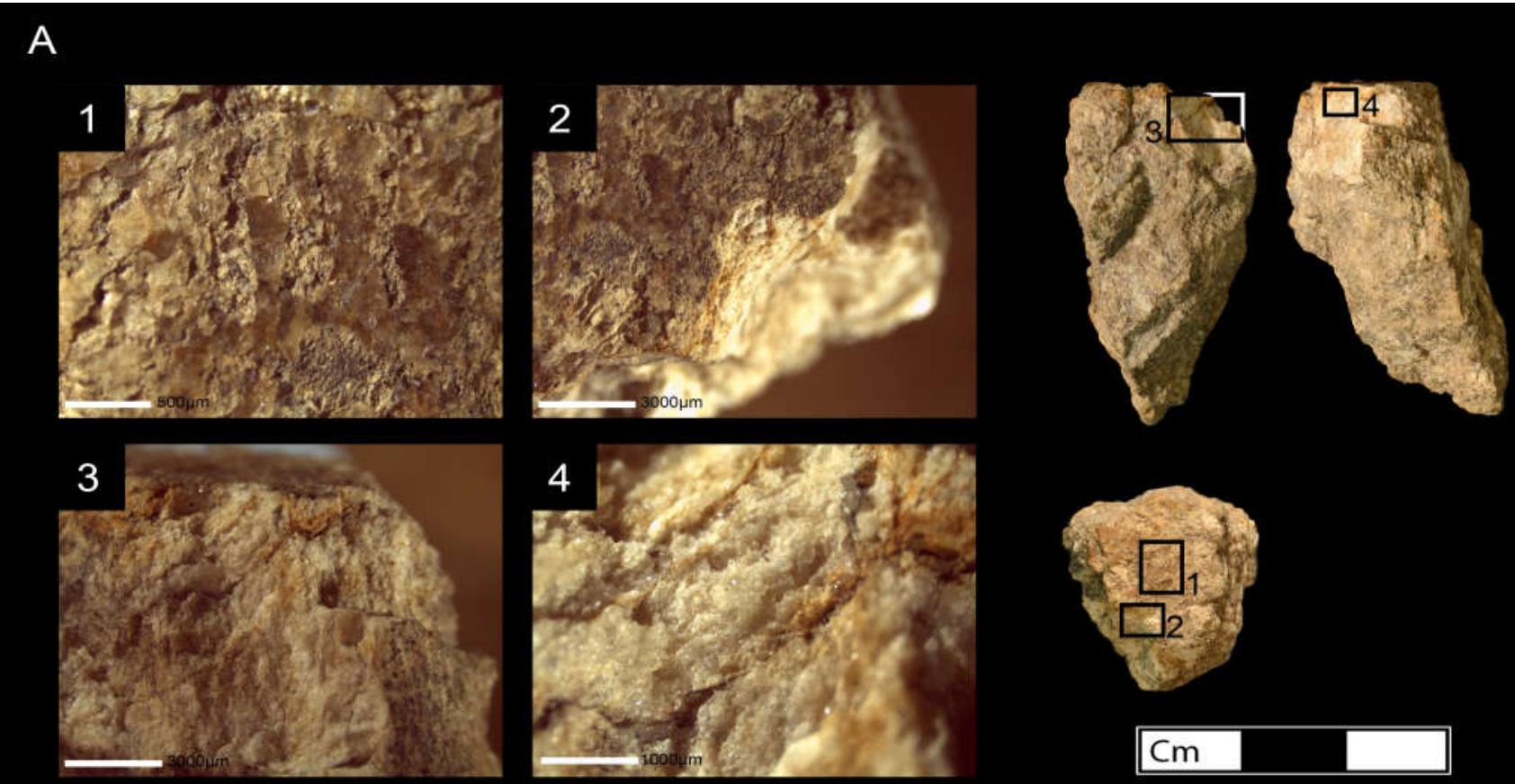

B
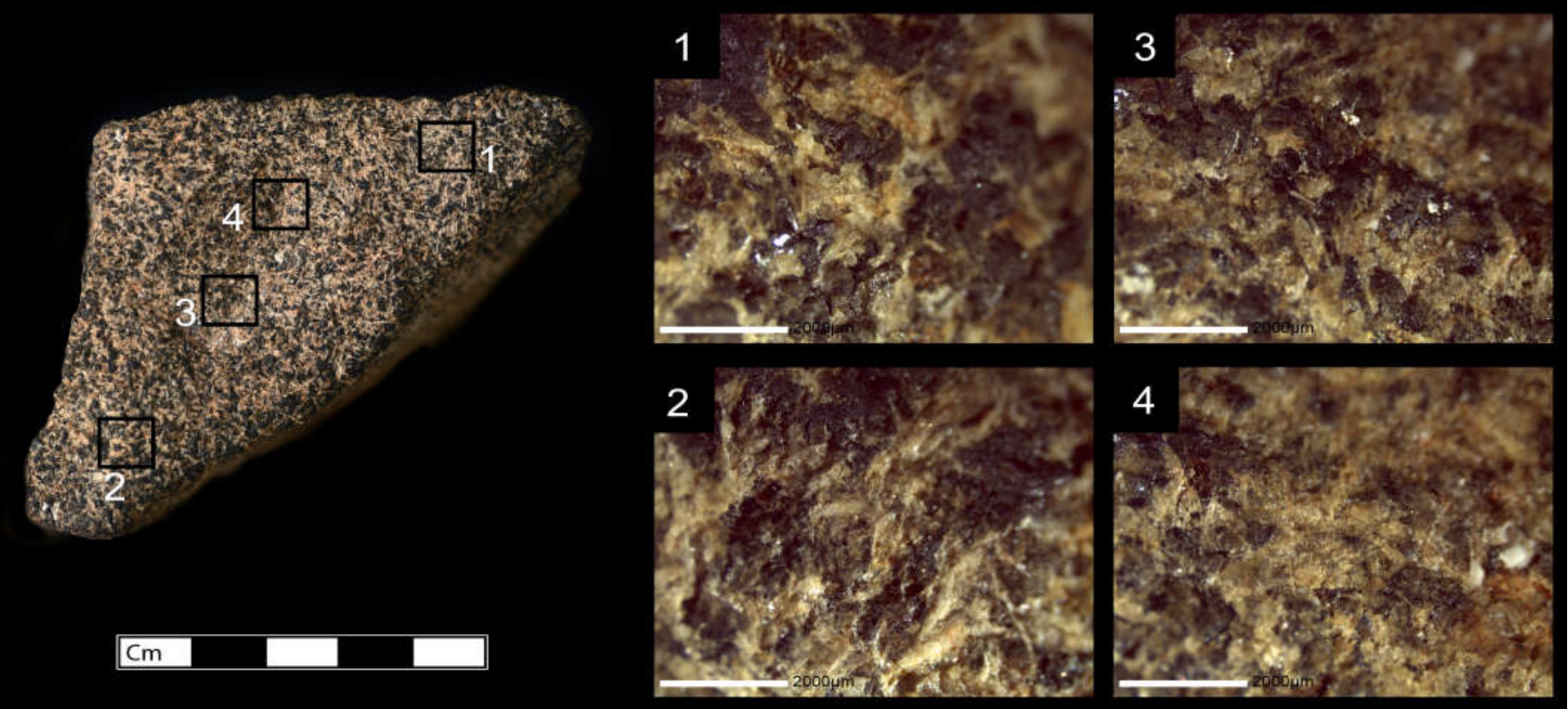

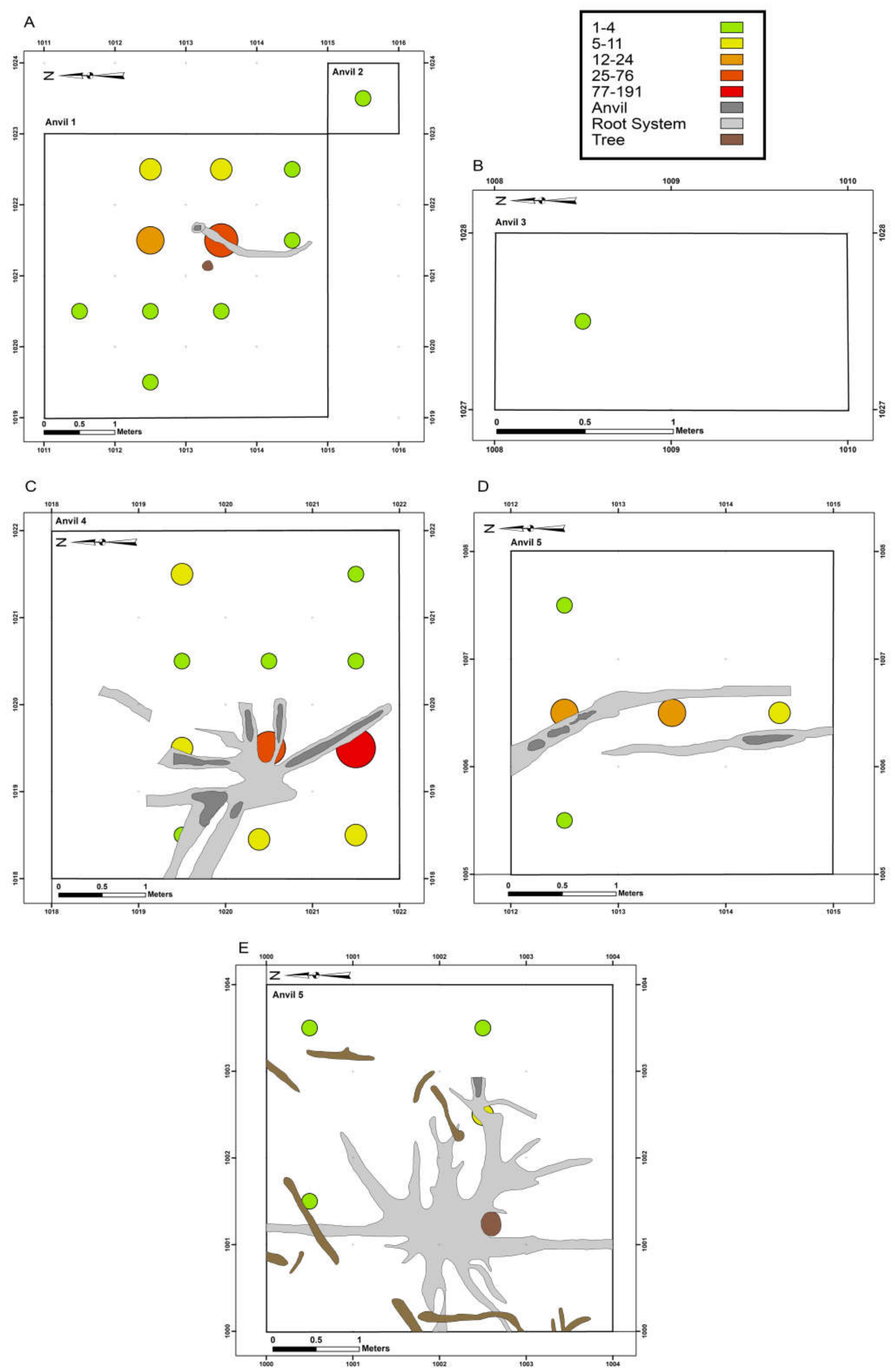


\section{Supplementary Material 2 \\ Panda 100 Refit Analyses}

\section{Refit Set 1:}

Refit Set 1 (Figure 4) is comprised of two angular chunks from a small laterite cobble, one of which was originally reported as a hammer fragment (Mercader et al., 2002, Fig. 2A). Both pieces were recovered from the same meter square at Anvil 4 with a horizontal distance of 0.21 meters, and are derived from spits 1 and 2 suggesting a degree of vertical movement (Table 4).

This cobble fractured into four separate pieces, two of which are represented in the refit and two by unrefitted fractures. No macroscopic evidence of percussive damage associated with the fracturing of the cobble is identifiable. However, a small area of wedge initiated fracturing on a convex protrusion on Plane A, which spans both refitted pieces, may be a result of percussive impact. The cortex of the cobble is highly weathered and smooth, with no evidence of percussive related pitting or crushing.

Although not fully refitted, the maximum dimensions of the cobble are apparent $(60.5 \mathrm{x} 56.9 \mathrm{x}$ $45.5 \mathrm{~mm}$ ). Ordinarily chimpanzee hammerstones used for Panda nut processing are considerably larger, possessing a mean weight of up to $17 \mathrm{~kg}$ (Boesch and Boesch, 1984a; Luncz et al., 2016). Because of its diminutive size, the cobble represented in Refit Set 1 is therefore unlikely to have been used as a Panda nut hammerstone. This finding does not preclude its use for processing other, more easily cracked nut species such as $C$. edulis, provided those activities left little surficial evidence of percussive damage, however P100 is an isolated Panda tree with no C. edulis sources close by. Conversely, it is known that infant nut cracking experimentation involves the use of smaller sized hammerstones.

\section{Refit Set 2}

Refit Set 2 (Figure 4) is the only refit identified in the original excavation report (Mercader et al., 2002, Fig 2E). This set represents a distally fractured, detached corner fragment of a diorite hammerstone. It includes a single corner fragment and a single edge fragment. There is little evidence of percussive damage observable on either piece, however, the clean nature of the ventral fracture suggests that this piece was detached through a relatively high degree of force.

The refitted fragments are derived from adjacent metre squares within the vicinity of Anvil 4, representing between 1-2 m of horizontal movement. A degree of vertical movement is also represented, between spits 0 and 1 (Table 4). As the smaller distal piece does not possess any identifiable impact point and is clearly derived from the same detachment event as the larger corner fragment, any spatial patterning between the two should not be associated with chimpanzee movement. 
Refit Set 2 provides insight into the original morphology of the diorite hammerstones used for Panda nut processing at P100. The refit preserves portions of Planes A, B and the opposed Plane A2, indicating a tabular morphology of the original hammerstone with a minimum thickness of $73.1 \mathrm{~mm}$. The active plane possessed a flat morphology, as indicated by the preserved platform on the larger of the two refitted pieces. No previous detachments are present on the dorsal surface of this corner fragment, indicating that this fragment was detached from an unbroken surface.

\section{Refit Set 3}

Refit Set 3 (Figure 5) consists of four granitoid fragments: two edge (Group 1.1) and two corner fragments (Group 1.2). Combined, this refit set represents the fragmentation of the corner and associated edge region of a hammerstone. A series of discreet impact points in association with small areas of crushing located on a single plane of the reconstructed set indicates the location of the active percussive plane (Plane A), as well as suggesting the direction of the detachments.

At least two separate fragmentation events are represented by this refit. The first occurred within close proximity to Anvil 4, and the second at Anvil 1, a horizontal transport of $9.54 \mathrm{~m}$ and a vertical movement between spits 1-2 (Table 4). The first fragmentation stage included the detachment of a singular edge piece and associated corner fragment. At some point following these detachments the hammerstone was transported from Anvil 4 to Anvil 1, where a second sequence of fracturing involved one edge fragment and one corner fragment being detached from the same corner area as the initial fragmentation. The close proximity of the two sequences of detachments might be either due to an internal weakness within this area of the hammer, as seen in the presence of a significant fracture plane on the ventral surfaces of all pieces within the refit, or it may have occurred due to continuing use of the same active plane.

The morphology of the original hammerstone can be partially reconstructed from the completed refit set. Plane A of the refit is a cortical surface, with relatively rounded margins and a slightly weathered surface, while Plane A2 possess the flat morphology of a fracture plane of the original granitoid block. The presence of percussive impacts on the cortical Plane A suggests that this surface was the active percussive plane, and that Plane A2 represents the outer surface of the original hammerstone at the point of this fragmentation sequence. The minimum length or width of the original hammerstone cannot be determined, but the minimum thickness was around $35 \mathrm{~mm}$.

\section{Refit Set 4}


Refit Set 4 (Figure 5) is a corner region of a granitoid hammerstone, consisting of one corner and one edge fragment. Both pieces were recovered from the vicinity of Anvil 1, from neighbouring meter squares, representing between 1-2 m of horizontal movement within a single spit (Table 4).

Similar to other refitted sequences, Refit Set 4 records the detachment of the edge of a hammerstone as well as detachment of the intersecting edge of Plane A and B. Initially a small corner area of the hammerstone was detached, followed by a larger edge piece. The superimposed fragmentation of these edge margins rapidly reduces the dimensions of the hammerstone. The direction in which the fracture occurred, seen in the step termination of the corner fragment, makes it likely that a previously fractured, non-cortical surface (Plane A) was the active percussive plane at the time of breakage, although the cortical Plane $\mathrm{C}$ may also have been the active plane resulting in this detachment.

\section{Refit Set 5}

Refit Set 5 (Figure 6) is comprised of two angular chunks (Group 2.2) which refit along an internal fracture plane. No percussive impact points, nor the active percussive plane from which these fragments originated, are identifiable. The pieces were recovered from neighbouring squares at Anvil 4 representing $1.27 \mathrm{~m}$ of horizontal movement between spits $0-1$ (Table 4).

\section{Refit Set 6}

Refit Set 6 (Figure 6) records the invasive detachment of a corner region of a granitoid hammerstone, caused by the hammerstone splitting along an internal fracture plane. It is comprised of three tabular fragments, two corner fragments and a single angular chunk. All refitted pieces were located in a single metre square at Anvil 4, representing a horizontal movement of $0.26 \mathrm{~m}$ within a single spit (Table 4).

The presence of significant internal fracture planes within the P100 granitoid hammerstones has contributed to their increased rate of fragmentation, and would have resulted in significant mass loss during percussive activities. The pieces in Refit Set 6 fragmented through a forceful wedging initiation that detached a corner region of a tabular hammerstone in its entirety. The sequence of fragmentation can be inferred by the presence of macroscopically visible impact points on the cortical platform of the edge fragment, suggesting the initial detachment of an elongated corner fragment that subsequently broke into at least two separate pieces. This event was followed by the detachment of an edge fragment as well as at least one internal angular fragment. These detachments spanned the entire thickness of the hammerstone. The cortical outer surfaces are preserved at both distal and proximal ends of the refit and can be used to estimate a minimum thickness of the original hammerstone of $62.4 \mathrm{~mm}$.

\section{Refit Set 7}


Refit Set 7 (Figure 6) comes from a roughly tabular, granitoid hammerstone. It includes three corner fragments and one edge fragment. All pieces are derived from two neighbouring metre squares at Anvil 4 representing a horizontal movement of $1.34 \mathrm{~m}$ between spits $0-1$ (Table 4 ).

Protruding angular regions of the hammerstone, located around its edges, readily broke during use. This refit represents a minimum of two separate impacts, the first detaching a large corner fragment. This piece overlays, and therefore precedes, the later breakage of a group of three fragments that may have been detached at the same time due to a single percussive impact. This fragmentation occurred with no rotation of the hammerstone, from the same active percussive plane (Plane A), and it detached a substantial volume of the corner and edge of the hammerstone as well as reaching the opposite plane.

A central void, where the remaining volume of the hammerstone would be located, could not be refitted and in all likelihood indicates that the remainder of the hammerstone was removed by chimpanzees from the anvil location after the refit set was detached. The refit preserves very little identifiable percussive damage on its cortical surfaces.

\section{Refit Set 8}

Refit Set 8 (Figure 7) documents the fragmentation of the edge of a tabular granitoid hammerstone and is comprised of two pieces: a corner fragment and a single edge fragment. Both pieces are found in neighbouring meter squares at Anvil 4 representing a horizontal movement of $0.83 \mathrm{~m}$ within a single spit. Fragmentation occurred along a pre-existing internal fracture plane, which detached the corner of the hammerstone. These flat internal fracture planes have been identified in a number of fragmented pieces, and result in the fragments possessing a broadly tabular morphology. Both horizontal planes (A and A2) are preserved in this refit set, indicating a minimum thickness of $50 \mathrm{~mm}$ of the hammerstone at the breakage point.

\section{Refit Set 9}

Refit Set 9 (Figure 7) represents minor fragmentation of a laterite cobble, consisting of one edge fragment and one angular chunk. This refit provides a case of inter-anvil transportation, between Anvil 2 and Anvil 5, which is a horizontal transport distance of $17.12 \mathrm{~m}$ within a single spit (Table 4). The direction of travel is unknown as it is not possible to ascertain the order of fragmentation. No clear percussive damage is evident on either conjoining piece, however, its percussive origin is confirmed by the significant conjoining distance. The angular chunk represented in this refit, was used in the initial report as an example of a laterite flake (Mercader et al., 2002, Fig 3I). Refit Set 9, however, allows a clearer understanding of process behind the detachment of this chunk, which bears no evidence of flake 
detachment and does not have the morphological characteristics of a detached flake nor is it detached from a position of the cobble which would have produced a flake detachment.

\section{Refit Set 10}

Refit Set 10 (Figure 8 ) is one of the most extensive refits at P100, and records significant fragmentation of a granitoid percussive hammerstone. It is comprised of five fragments: three corner fragments (Group 1.2), one interior angular chunk (Group 2.2) and one indeterminate angular chunk (Group 4).

This refit set represents the transport of a hammerstone between Anvil 4 and Anvil 5, totalling a distance of $16.59 \mathrm{~m}$ between two spits (Table 4). The fragmentation sequence can be determined based on the spatial mapping of this refit set. A single small cortical angular chunk was detached spontaneously from the exterior of Plane B2 at Anvil 5. This was followed by a transportation of the hammerstone to Anvil 4, where the majority of the fragmentation occurred. Plane A was used as the active percussion plane, shown by an area of crushing and slight pitting. As no other areas of percussive damage are identified this fragmentation appears to result from a single strike in combination with a number of internal fracture planes.

This refit set also provides a wider context to the illustrated pieces identified in the original P100 publication (Mercader et al., 2002, Fig 3A), allowing for a refinement of its classification. In this case, a large corner fragment, originally described as a partially cortical flake with evidence of previous removals is instead a product of an internal fracture plane, with no previous dorsal surface extractions, no impact point or knapping platform, no bulb of percussion and no evidence of previous removals, instead possessing a distinct patina. This piece instead is a fine example of a corner fragment, similar in many respects to those identified in previous studies at early hominin archaeological sites (De la Torre and Mora, 2005).

\section{Refit Set 11}

Refit Set 11 (Figure 8) consists of two fragments, one angular chunk and one edge fragment, which combine to form an edge piece that fractured laterally during its removal. The spatial data for one of these pieces is not available and as such it is impossible to identify the horizontal and vertical conjoining distance (Table 4).

The dorsal surface of this detachment preserves at least one previous removal from the side of the original hammerstone, indicating the repeated fragmentation of this stone along its edges and margins. The result was an increasingly rounded edge as the non-invasive edge fragments were detached. Refit Set 11, however, also records the second main fragmentation sequence at P100. In that sequence a 
hammerstone exhibits significant volume loss through the 'slicing' of the edge of the hammerstone, with both the active plane and opposite surface detached at once, following initial minor edge fragmentation.

\section{Refit Set 12}

Refit Set 12 (Figure 8 ) includes five fragmented pieces, consisting of two edge fragments (Group 1.1), and three angular chunks / fragments (Groups 2.2 and 4). Although highly fragmented all pieces are derived from anvil 1 and represent a horizontal conjoining distance of $1.49 \mathrm{~m}$ between three spits (Table 4). The refit retains evidence of two active percussive surfaces, bearing impact marks. Two pieces retain percussion marks in the form of localised crushing, which in one case resulted in the detachment of an edge fragment with an associated second removal of an internal angular chunk. In the second instance the percussive damage is located on the cortical surface of plane $\mathrm{C}$, and is characterised as crushing that did not directly result in breakage of the hammerstone. For three of the five refitted fragments there is no clear association with percussive force, however, these fragments do possess clearly non-cortical surfaces suggesting an indirect fragmentation associated with percussive force. The detachment of these fragments can be explained by the poor quality, fractured, coarse grained and non-homogenous raw material.

Similar to other refit sets, this refit represents the gradual attrition of the edge and exterior regions of a nut cracking hammerstone. This process is seen in the detachment of both small and large angular edge and corner fragments, gradually reducing the overall volume of the hammerstone. 


\section{Supplementary Material 3: GIS Maps}

\section{Map of Panda 100 excavation}

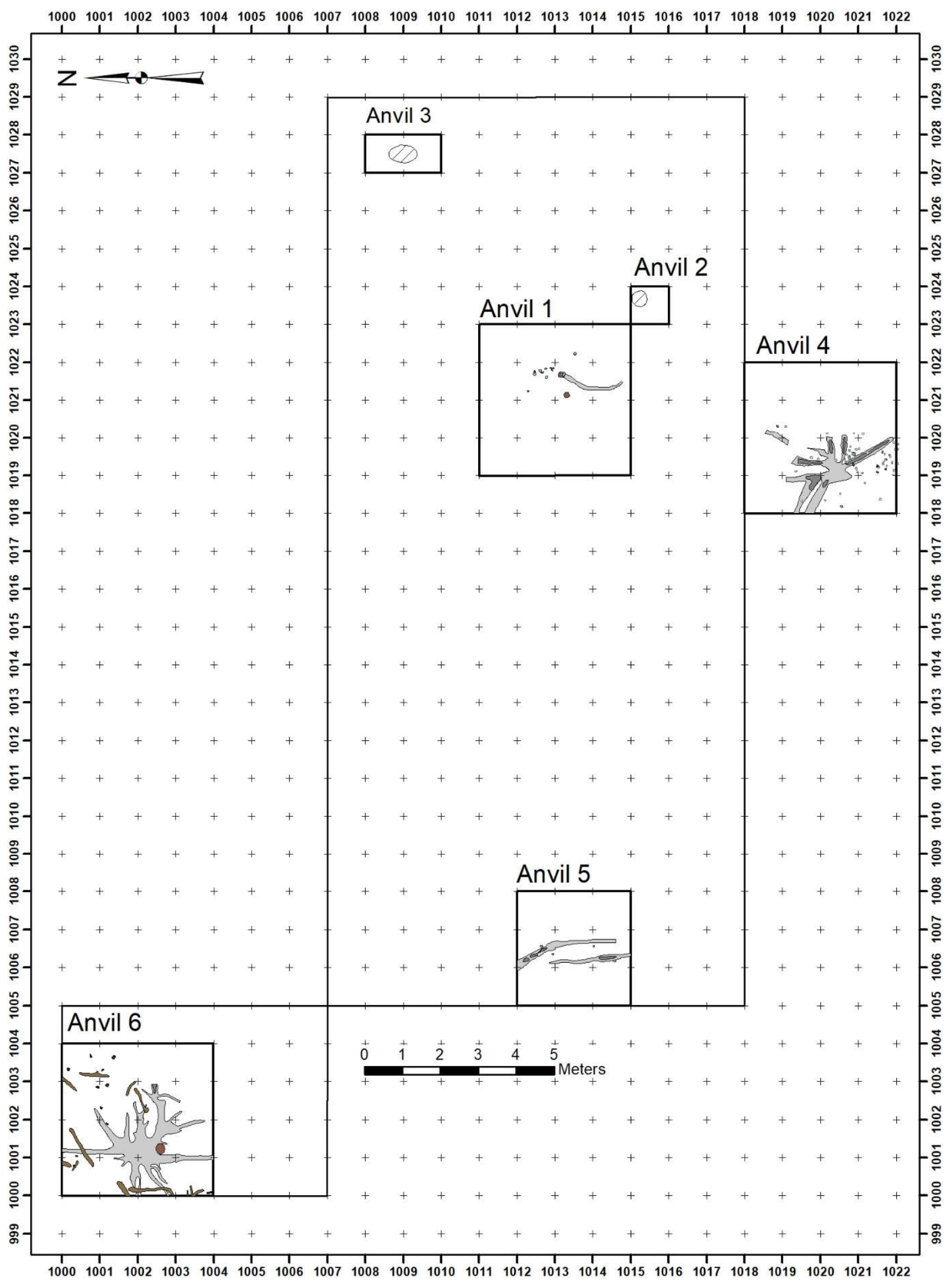


Updated Map of Panda 100 Anvil 1

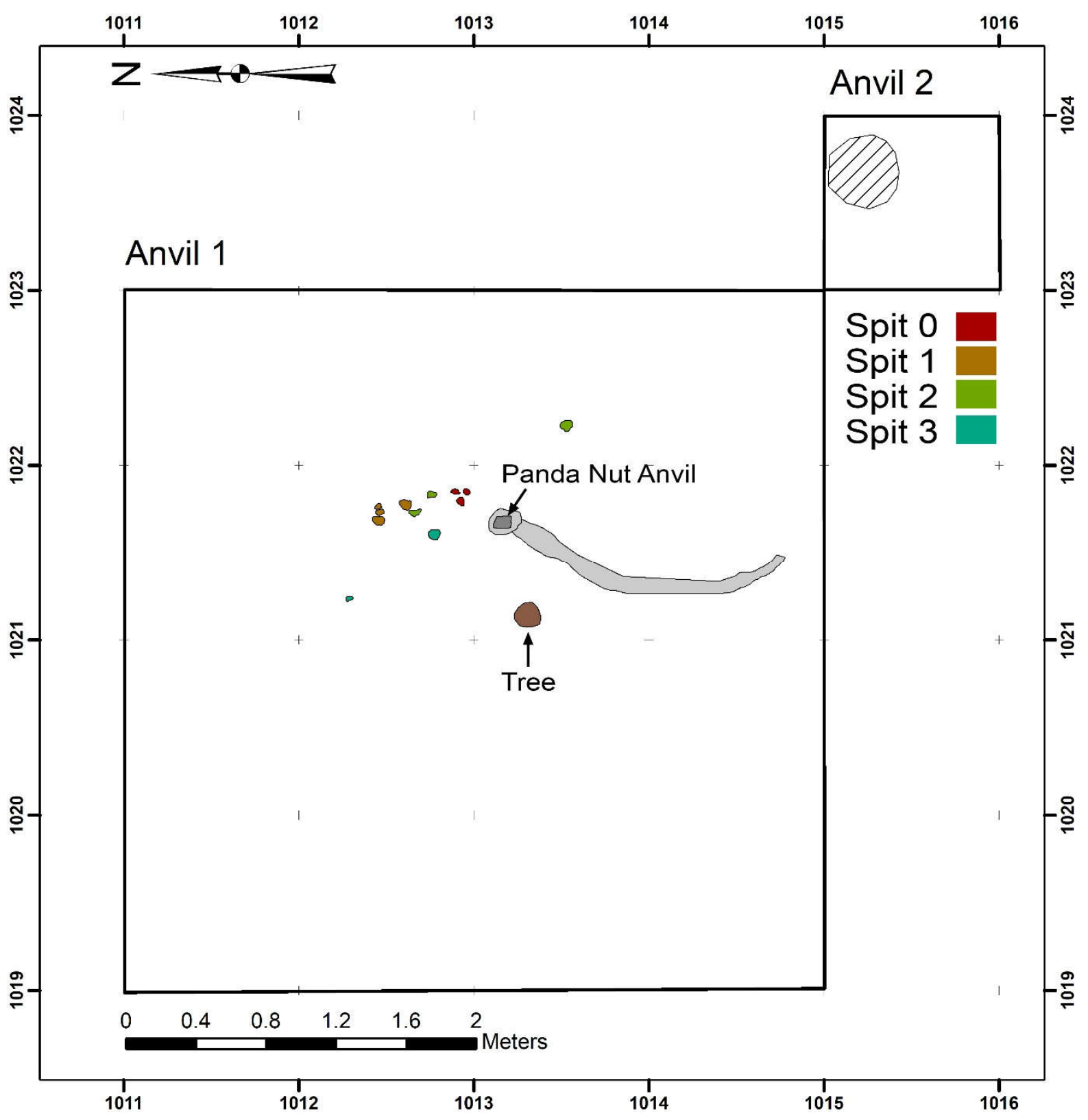




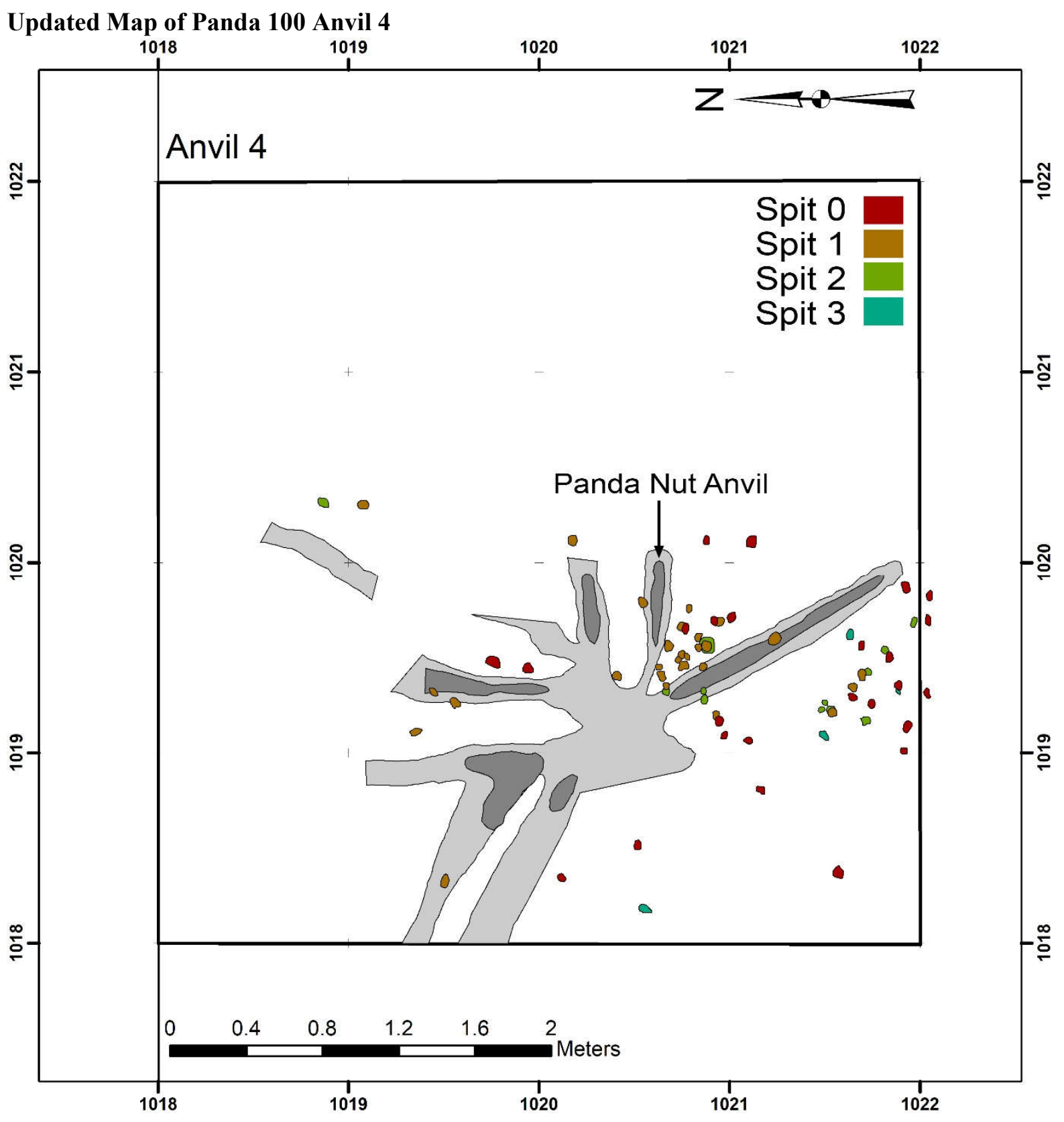




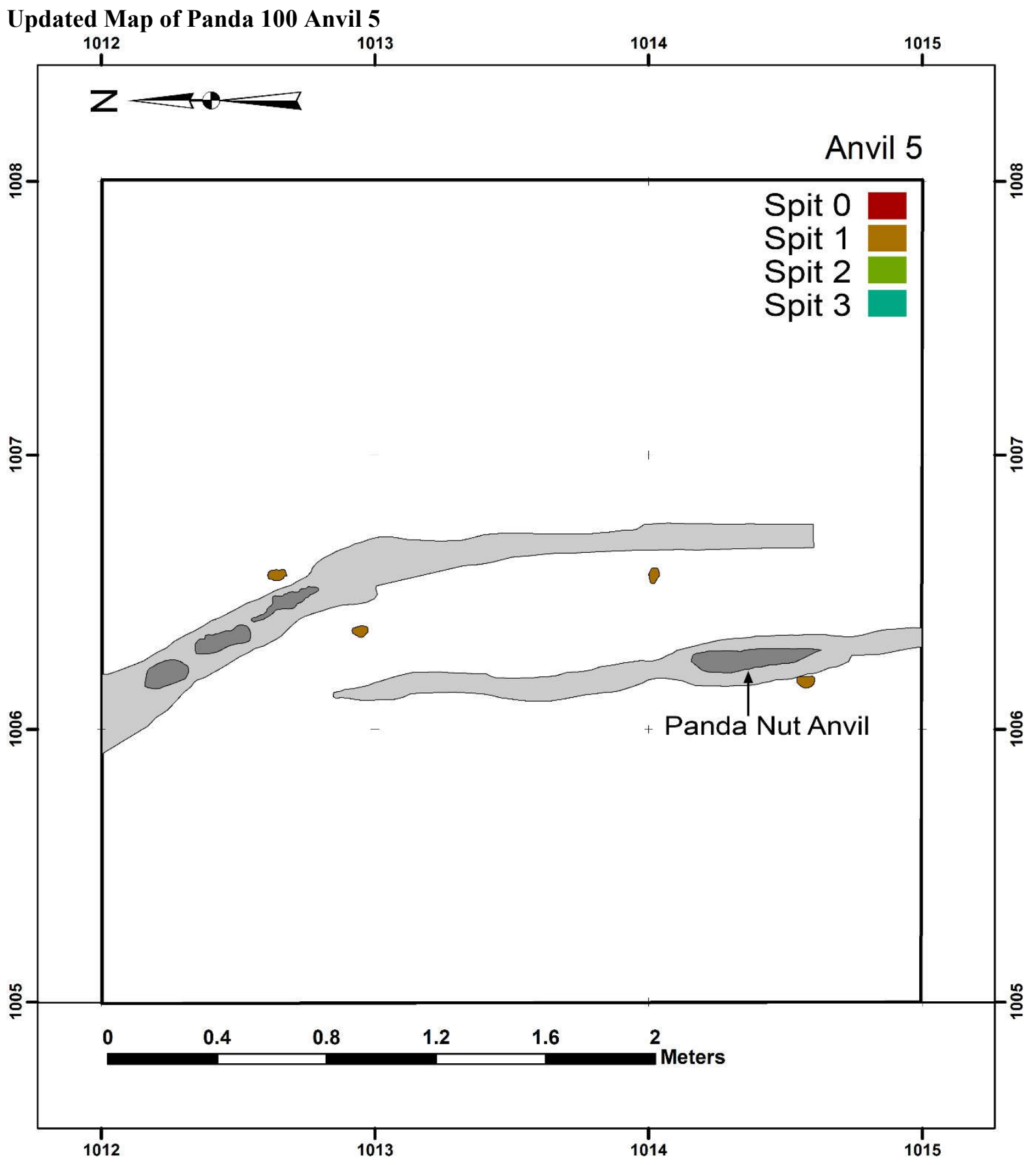


Updated Map of Panda 100 Anvil 6

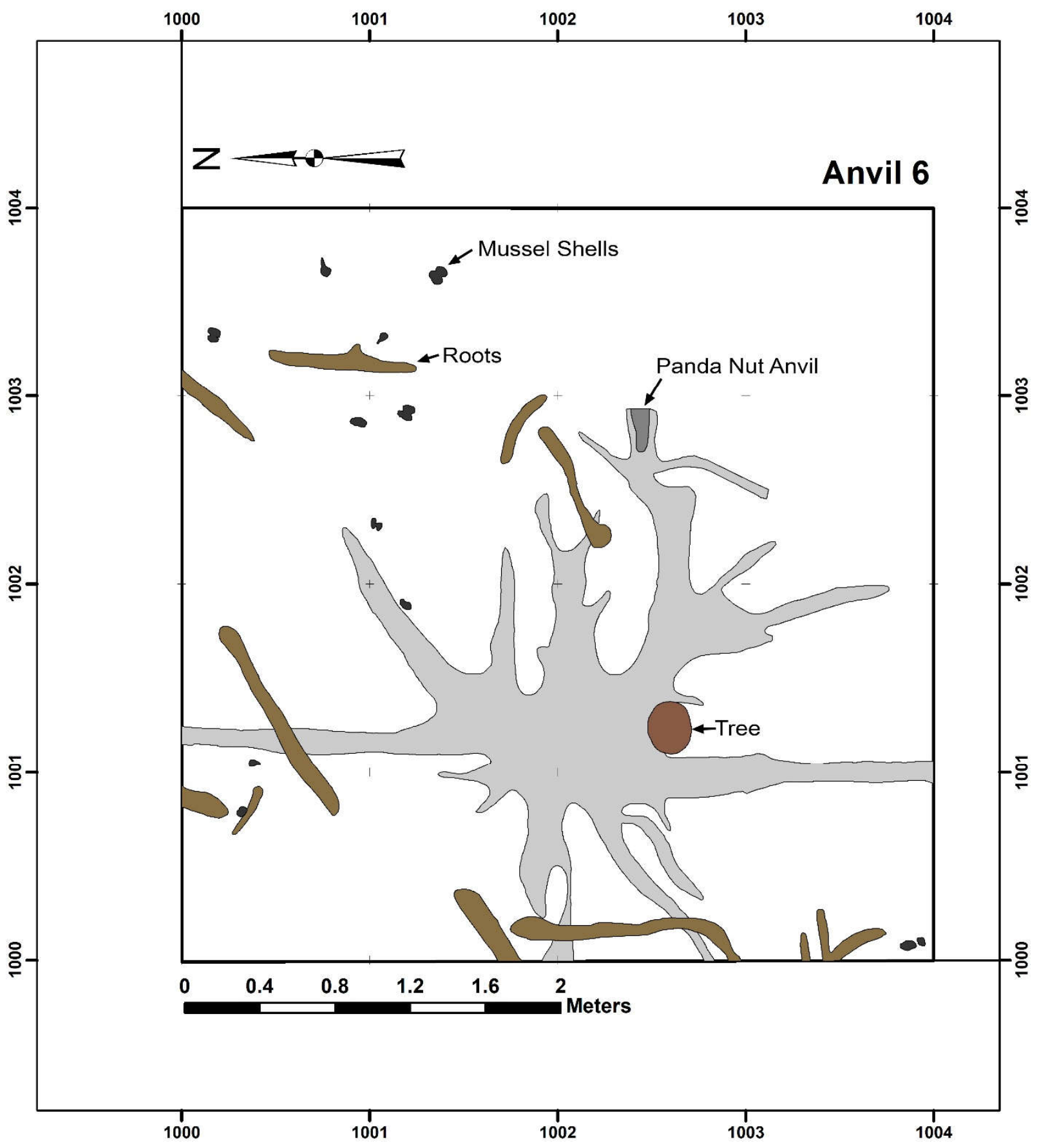

